\title{
A Review of the Use of Carbon Nanotubes and Graphene-Based Sensors for the Detection of Aflatoxin M1 Compounds in Milk
}

\author{
Jingrong Gao ${ }^{1, \dagger}$, Shan $\mathrm{He}^{2,3, *,+}$, Anindya Nag ${ }^{4, *}$ and Jonathan Woon Chung Wong 5 \\ 1 School of Food Science and Engineering, South China University of Technology, Guangzhou 510640, China; \\ gaojingrong@scut.edu.cn \\ 2 Institute for NanoScale Science and Technology, College of Science and Engineering, Flinders University, \\ Bedford Park 5042, Australia \\ 3 School of Chemistry and Chemical Engineering, Guangzhou University, Guangzhou 510006, China \\ 4 School of Information Science and Engineering, Shandong University, Jinan 251600, China \\ 5 Institute of Bioresource and Agriculture, Hong Kong Baptist University, 224 Waterloo Road, \\ Kowloon Tong 999077, Hong Kong, China; jwcwong@hkbu.edu.hk \\ * Correspondence: shan.he@flinders.edu.au (S.H.); anindya1991@gmail.com (A.N.) \\ + These two authors contributed equally to this work.
}

\section{check for}

updates

Citation: Gao, J.; He, S.; Nag, A.; Wong, J.W.C. A Review of the Use of Carbon Nanotubes and Graphene-Based Sensors for the Detection of Aflatoxin M1 Compounds in Milk. Sensors 2021, 21, 3602. https://doi.org/10.3390/ s21113602

Academic Editors: Simone Morais, Álvaro Miguel Carneiro Torrinha and Iria Bravo

Received: 28 April 2021

Accepted: 20 May 2021

Published: 21 May 2021

Publisher's Note: MDPI stays neutra with regard to jurisdictional claims in published maps and institutional affiliations.

Copyright: (c) 2021 by the authors. Licensee MDPI, Basel, Switzerland. This article is an open access article distributed under the terms and conditions of the Creative Commons Attribution (CC BY) license (https:// creativecommons.org/licenses/by/ $4.0 /)$.

\begin{abstract}
This paper presents a comprehensive review of the detection of aflatoxin compounds using carbon allotrope-based sensors. Although aflatoxin M1 and its derivative aflatoxin B1 compounds have been primarily found in milk and other food products, their presence above a threshold concentration causes disastrous health-related anomalies in human beings, such as growth impairment, underweight and even carcinogenic and immunosuppressive effects. Among the many sensors developed to detect the presence of these compounds, the employment of certain carbon allotropes, such as carbon nanotubes (CNTs) and graphene, has been highly preferred due to their enhanced electromechanical properties. These conductive nanomaterials have shown excellent quantitative performance in terms of sensitivity and selectivity for the chosen aflatoxin compounds. This paper elucidates some of the significant examples of the CNTs and graphene-based sensors measuring Aflatoxin M1 (ATM1) and Aflatoxin B1 (AFB1) compounds at low concentrations. The fabrication technique and performance of each of the sensors are shown here, as well as some of the challenges existing with the current sensors.
\end{abstract}

Keywords: carbon nanotubes; graphene; immunoassay; aflatoxin M1; aflatoxin B1

\section{Introduction}

The utilization of carbon allotropes in the sensing world has brought about revolutionary changes in recent times. After the popularization of sensors at the end of the 20th century, various MEMS [1,2] and printed [3,4] sensors have been fabricated and utilized in different applications. The semiconducting sensors hold the highest priority due to their high accuracy, high linearity, high signal-to-noise ratio and easy interfacing with the control systems [5,6]. The materials used to form these semiconducting sensors have evolved. Earlier, during the 1990s, silicon became the most popular material for forming the substrates of the sensors. This was due to its high stability and repeatability in the responses, the small size of the prototypes and ability to work in extreme conditions [7]. While silicon became a standard material to form the substrates until printed sensors came into the picture, the conductive elements used to form the electrodes were constantly changing. This is due to the direct relationship between the properties of the electrodes with that of the quality of the sensors. With the constant growth in nanotechnology [8-10], nanomaterials of various forms, including nanoparticles, nanobeads, nanosheets, nanopowders and quantum dots have been exploited to fabricate the electrodes. Although all of these materials are significant in enhancing the efficiency of the resultant devices, the electrical, 
mechanical and thermal attributes associated with each of them can differ based on their size, shape and dimensions.

Nanomaterials can be broadly classified into two categories, namely metallic nanoparticles $[11,12]$ and carbon-based allotropes. Among the former group, certain elements such as gold $[13,14]$, silver $[15,16]$, copper $[17,18]$ and aluminum $[19,20]$ have been extensively used in forming the electrodes. The deployment of these metallic elements has been mostly done using the conventional microelectrochemical systems (MEMS) technique [21]. Although all these nanomaterials have been utilized to develop sensors for a wide range of applications, biocompatibility is one critical parameter that needs approval before the use of the sensors for the healthcare sector. The biocompatibility of the sensor may decide the standard of the sensor and affect the condition of the patient. For example, suppose soluble silver compounds are used to form flexible sensors that are used as catheters. In that case, it can lead to certain toxic effects such as liver and kidney damage, irritation of the eyes and respiratory problems [22]. This biocompatibility can be addressed by using specific elements such as carbon-based allotropes. This category includes elements such as carbon nanotubes (CNTs) [23-25], graphene [26-28], graphite [29-31] and fullerenes [32-34]. Among these elements, CNTs and graphene have been extensively used for a wide range of applications. The biocompatibility of these elements depends strongly on certain factors such as mass, purity, ratio and surface functional groups [35]. In cases of electrochemical applications as the one shown in the paper, the functionalization of CNTs, graphene and their derivatives has increased the attention towards other nanomaterials to increase the biocompatibility towards biosensing applications. The surface modification also increases the dispersibility of these carbon-based structures as a result of the alteration of cellular interaction pathways. This decreases the cytotoxic effects of CNTs and graphene are tested in vitro conditions before the deployment in real-time scenarios [36].

Each of the above-mentioned conductive elements has been deposited and embedded either on silicon or a range of polymers such as polydimethylsiloxane (PDMS) [37,38], polyethylene terephthalate (PET) [39,40], poly(3,4-ethylene dioxythiophene) polystyrene sulfonate (PEDOT: PSS) [41,42] and polyimide (PI) [43,44]. The sensors formed with these elements have been used in a wide range of environmental [45-47] and industrial [48-50] sectors. Initially, CNTs were popularized in the late 90s for developing sensors for academic and industrial applications $[36,51,52]$. CNTs were synthesized in various forms based on the number of walls present in their structures. Two of the common forms, including single-walled carbon nanotubes (SWCNTs) $[53,54]$ and multi-walled carbon nanotubes (MWCNTs) [55,56], have been considered for application purposes. Apart from these two, there are double-walled carbon nanotubes (DWCNTs) $[57,58]$ and few-walled carbon nanotubes (FWCNTs) [59,60], but these are mostly used for characterization purposes. Some of the synthesis processes used to develop CNTs are chemical vapor deposition (CVD) [61,62], arc-discharge [63,64], laser ablation [65,66] and liquid electrolysis [67,68]. The selection of each of these processes depends on the type of CNTs required for the chosen application. Graphene has been proclaimed to be a magic material since its synthesis on a research scale [69]. Scientists have tried fabricating graphene in various ways to increase its availability at a reduced cost. Some of the common techniques of synthesizing graphene are CVD [70,71], Hummers' method [72,73] and laser ablation of commercial films $[74,75]$. Graphene has been utilized for a wider sector of applications in comparison to CNTs due to its enhanced electromechanical properties. It has been used in pure and composite [76,77] forms to build robust and highly sensitive sensors. Table 1 [78] shows a comparison between CNTs and graphene in terms of their physicochemical properties. It is seen that both these elements have been highly efficient in the sensing world. This paper showcases the use of sensors based on these elements to detect a particular chemical found in food products. 
Table 1. Comparison between CNTs and graphene based on certain physicochemical properties [78].

\begin{tabular}{|c|c|c|}
\hline $\begin{array}{l}\text { Physiochemical } \\
\text { Properties }\end{array}$ & Graphene & Carbon Nanotubes \\
\hline Shape & Planar: monolayer or multi-layer & Cylindrical (SWCNTs, DWCNTs, MWCNTs) \\
\hline Dimensions & $\begin{array}{l}\text { - } \quad \text { Thickness: } 0.34-100 \mathrm{~nm} \\
\text { - } \quad \text { Lateral size: } 0.3-10 \text { microns }\end{array}$ & $\begin{array}{l}\text { - SWCNT length: } 10 \mathrm{~nm} \text { to } 1 \mathrm{~cm} \text {, diameter: } \\
0.4 \text { to } 3 \mathrm{~nm} \\
\text { MWCNT length: } 10 \mathrm{~nm} \text { to few microns, } \\
\text { diameter: } 2 \text { to } 200 \mathrm{~nm}\end{array}$ \\
\hline Surface & $\begin{array}{l}\text { - Up to } 275 \mathrm{~m}^{2} / \mathrm{g} \text {, decreases with an increase in } \\
\text { the number of layers. } \\
\text { - Varies with functionalization or coating. } \\
\text { Varies in chemical nature, type, density and } \\
\text { conformation. }\end{array}$ & $\begin{array}{l}\text { - SWCNTs }\left(>1000 \mathrm{~m}^{2} / \mathrm{g}\right), \text { MWCNTs } \\
\left(100-500 \mathrm{~m}^{2} / \mathrm{g}\right) \\
\text { - } \quad \text { Varies with functionalization or coating. } \\
\text { Varies with chemical nature, type, density } \\
\text { and confirmation. }\end{array}$ \\
\hline Elasticity/stiffness & $\begin{array}{l}\text { - } \quad \text { Young's modulus: } 1100 \mathrm{GPa} \\
\text { - } \quad \text { Capable of bending and rippling } \\
\text { - } \quad \text { Stiffness increases with the number of layers }\end{array}$ & $\begin{array}{l}\text { - } \quad \text { SWCNTs: } 1 \text { to } 5 \mathrm{TPa} \text {, capable of bending } \\
\text { - } \quad \text { MWCNTs: } 0.2 \text { to } 0.95 \mathrm{TPa}\end{array}$ \\
\hline Colloidal stability & $\begin{array}{l}\text { - Dispersion: Graphene oxide in water } \\
\text { - } \quad \text { Aggregation: Stacking }\end{array}$ & $\begin{array}{l}\text { - } \quad \text { Dispersion: Oxidized CNTs in water } \\
\text { - } \quad \text { Aggregation: Bundling and tangling }\end{array}$ \\
\hline Durability & Enzymatic degradation by defects in the plan & $\begin{array}{l}\text { Enzymatic degradation by unzipping and decrease } \\
\text { in length and diameter }\end{array}$ \\
\hline Impurities & $\begin{array}{l}\text { Varies after the manufacturing process, mainly } \\
\text { graphite and chemical residues after processing. }\end{array}$ & $\begin{array}{l}\text { Varies after the manufacturing process, metal } \\
\text { catalysts }(\mathrm{Fe}, \mathrm{Co}, \mathrm{Ni}, \mathrm{Cr}, \mathrm{Cu}, \mathrm{Zn}) \text {, carbon } \\
\text { nanoparticles, amorphous carbon }\end{array}$ \\
\hline
\end{tabular}

The use of sensors for electrochemical sensing has been a cornerstone in recent times. Different kinds of MEMS and printed prototypes have been used to detect chemical compounds present in solutions at varied concentrations. The use of CNTs and graphene in sensors for electrochemical sensing has been very efficient due to their high electrical conductivity and charge carrier densities. Out of the applications related to electrochemical sensing, the detection of ions present in food is critical, as a slight aberration in the concentration of the chemical from its optimized value can increase the toxicity of the food product. Among them, aflatoxin M1 (ATM1) is one of the chemical compounds from a group and species of mycotoxins and aspergillus, respectively, that is found in milk and other food products [79-81]. While this chemical is primarily present in animal milk, the increase in its concentration can lead to adverse effects on the central nervous system, liver, kidney. It may even cause death [82]. Thus, despite the pasteurization and sterilization of the milk before its consumption, it is important to determine the precise concentration of ATM1. Scientists have trying to fabricate sensors for detecting ATM1 with a combination of different kinds of conductive elements and semiconducting/insulating substrates.

Table 2 shows a comparison between the performances of the sensors based on different detection techniques. Each of these sensors detecting ATM1 compounds is capable of generating excellent analytical performances. This paper explains the use of sensors formed using CNTs and graphene for the detection of ATM1. Followed by the introduction stating the need for CNTs and graphene-based sensors and their deployment to detect ATM1, Section 2. explains some of the significant kinds of prototypes that are fabricated and utilized for the target application. This section is sub-categorized into two parts based on the type of conductive element used to fabricate the sensors. The third section highlights some of the challenges related to the current sensors and their possible remedies. The conclusion is drawn in the final section of the paper. 
Table 2. Comparison between the performances of the sensing prototypes based on different detection techniques.

\begin{tabular}{|c|c|c|c|c|}
\hline Sensor Materials & Detection Technique & Detection Analyte & Analytical Performance & Ref. \\
\hline $\begin{array}{l}\text { Graphene } \\
\text { nanoribbons }\end{array}$ & Dynamic light scattering & AFB1 & $\begin{array}{l}\text { - } \quad \text { Linear range: } 0.5-20 \mathrm{ng} / \mathrm{mL} \\
\text { LOD: } 0.16 \mathrm{ng} / \mathrm{mL}\end{array}$ & [83] \\
\hline $\begin{array}{l}\text { Graphene oxide, } \\
\text { Au NPs, PEDOT }\end{array}$ & Impedance spectroscopy & AFB1 & $\begin{array}{l}\text { - Linear range: } 0.5-20 \mathrm{ng} / \mathrm{mL} \text {, } \\
\text { 20-60 } \mathrm{ng} / \mathrm{mL} \\
\text { - LOD: } 0.109 \mathrm{ng} / \mathrm{mL}\end{array}$ & [84] \\
\hline $\begin{array}{l}\mathrm{Fe}_{3} \mathrm{O}_{4}, \mathrm{GO}, \mathrm{CdTe} \\
\text { quantum dots, } \\
\text { CNTs }\end{array}$ & Electrochemiluminescence & ATM1 & $\begin{array}{ll}\text { - } & \text { Linear range: } \\
& 1.0-1.0 \times 10^{5} \mathrm{pg} / \mathrm{mL} \\
\text { - } & \text { LOD: } 0.3 \mathrm{pg} / \mathrm{mL}\end{array}$ & [85] \\
\hline $\begin{array}{l}\text { rGO, polyaniline, } \\
\text { MoS }_{2} \text {, glassy } \\
\text { carbon electrode, } \\
\text { Au NPs }\end{array}$ & $\begin{array}{l}\text { Differential pulse } \\
\text { voltammetry }\end{array}$ & AFB1 & $\begin{array}{l}-\quad \text { Linear range: } 0.01-1.0 \mathrm{fg} / \mathrm{mL} \\
\text { - } \quad \text { LOD: } 1.0 \mathrm{fg} / \mathrm{mL}\end{array}$ & [86] \\
\hline $\begin{array}{l}\text { Au NPs, } \\
\text { carboxymethyl- } \\
\text { dextran }\end{array}$ & Cyclic voltammetry & AFB1 & $\begin{array}{ll}\text { - } & \text { Linear range: } \mathrm{R}^{2}>0.99 \\
& \text { LOD: } 3.3\end{array}$ & [87] \\
\hline $\mathrm{Au}$ NPs & Thin layer chromatography & ATM1 & $\begin{array}{l}\text { - } \quad \text { Linear range: } 0-80 \mathrm{ng} / \mathrm{L} \\
\text { - } \quad \text { LOD: } 350 \mathrm{ng} / \mathrm{L}\end{array}$ & [88] \\
\hline
\end{tabular}

\section{Carbonaceous Sensors for the Detection of Aflatoxin MI Molecules}

The consideration of carbon nanostructures for detecting electrochemical sensing applications is significant due to their high sensing area, high aspect ratio and high electrical conductivity. These nanostructures have been able to detect chemical ions in the solutions for a wide range of concentrations. Different detection mechanisms are carried out to determine the changes in the ionic and faradic currents flowing between the electrodes and the tested samples. The changing current values occur due to the corresponding changes in the impedance values due to the specific electrode structures. CNTs and graphene have been utilized to form electrodes that display high selectivity and high sensitivity towards the ionic samples. The deployment of these sensors for food materials has been particularly essential due to their biocompatible nature. While graphene has been a magic material for sensorial operations, other CNT products have also been very efficient as a replacement of the metallic nanowires due to their resistant nature towards a wide range of temperature and humidity and ability to withstand extreme ambiance conditions in terms of heat and cold $[89,90]$. Both two-electrode and three-electrode systems were equally effective for detecting the ATM1 compound due to the high selectivity induced by these sensors. Electrochemical impedance spectroscopy [91,92] and cyclic voltammetry [93,94] were used to determine the changes in the impedance and current, respectively, due to the corresponding change in the concentrations of the samples.

The doping of these carbon allotrope-based electrodes has positively affected the selectivity and sensitivity towards the aflatoxin molecules. The change in the structural, morphological and electrochemical properties of these electrodes has increased the chargetransfer rate, thus increasing the electrochemical activity on the surface of the electrodes. This treatment is done using a range of active materials such as metallic nanoparticles and polymers that participate in the electrochemical redox reactions. The doping or alteration of the physiochemical nature of the electrodes is done through different techniques such as nanocomposite formation [95], pyrolysis [96], calcination [97] and reduction [98] processes. These treatment methods improve the electron transfer kinetics and charge carrier density at the electrode surface by instigating surface states and facilitating electron transfer [99]. The doped element would also sometimes have multifunctional roles, where a specific 
area of the electrodes would be activated multiple times as compared to the inactivated ones. This would create mesoporous structures that pave the way for new ionic and faradic reactions, contributing to the change in the output of the devices. The morphological changes can be ascribed to creating new defects on the graphene sheets and sidewalls of CNTs. The decreased amount of amorphous carbon compared to their pristine condition creates small clusters, thus modifying the surface of the particles and increasing their active surface sites. The inhomogeneity caused in the carbon allotropes, although increasing in the charge distribution across the carbon network, results in poor cyclability due to permanent structural changes [100].

The detection phenomenon of ATM1 is based on the ionic bonds formed on the sensing area of the electrodes. The presence of a large aromatic ring of ATM1 helps the sensors to adsorb the compound and separate it for analysis purposes. This helps the researchers to build prototypes that are highly selective towards this particular compound. Although other molecules also consist of aromatic rings, the selectivity generated on the electrodes assists in sensing the aflatoxin molecules. This selective nature can be achieved in multiple ways. It can be done by using aptamers, which act as recognition elements [101]. Initially, aptamers are immobilized on the electrodes via covalent bonding. Then, electrochemical probes are formed with the presence of appropriate signal enhancement elements to induce a charge shift. This causes a change in response during the aptameter-specific recognition and binding of aflatoxin molecules at various levels. Other ways include the presence of nanoparticles such as gold or platinum on the carbon-based electrodes. The presence of these additional nanoparticles modifies the resultant electrocatalytic behavior of the electrodes, thus responding to the aflatoxin molecules when monitored through voltammetry and impedimetric techniques [84]. The selectivity is also achieved through a label-free biosensing mechanism. Here, the carbon-based allotropes form conjugates with other selective nanomaterials and consequently mixes with free antibodies to increase the resultant absorption intensity. Sometimes, solutions such as bovine serum albumin (BSA) are used to increase the sensitivity by blocking the unspecified sites to prevent non-specific adsorption. Finally, the changes in responses of the sensors when treated with aflatoxin antigens are monitored using optical and electrochemiluminescent techniques [83].

When the prototypes are exposed to ATM1 in different concentrations, an adsorption process occurs, the rate of which initially increases and then gradually saturates over time. This equilibrium is attended due to the adsorption of ATM1 on the exterior surface of the adsorbent during the earlier phase of the contact time [85]. After a saturation occurs, the ATM1 ions diffuse from the exterior to the interior surfaces of the adsorbents. Different kinds of sensitive analytical methods are being employed to monitor the ultra-trace levels of ATM1 in milk and other food products. As a result of its strong toxic effects on public health, affordable, portable and efficient methods are devised for screening and detecting the ATM1 levels in the food products. The fabrication and implementation of these sensors have created a podium for further scientists to work on the quality control of the food molecules. Apart from this chosen molecule, other constituents can also be detected with multifunctional sensing systems formulated with carbon-based allotropes.

\subsection{Carbon Nanotube-Based Sensing Prototypes}

Before using graphene as a common carbon-based allotrope for a wide range of sensing applications, CNTs were highly favored due to their attributes. These sensors are particularly beneficial for these kinds of electrochemical sensing due to their sensing area due to their high aspect ratio. Due to the rolling up of graphene sheets into tubes to form CNTs, their electrochemical properties can be compared to the basal planes of the pyrolytic graphite. The cap regions of the CNTs have a higher reactivity due to the higher curve strain in comparison to the sidewall. In retrospect to the defect-free structures of these tubes, their physical and chemical treatments can induce a variety of oxygen-containing groups. This increases the number of binding sites for a particular chemical analyte $[99,102]$. The high electrical conductivity of CNTs also helps in electrochemical reactions by increasing the 
electron transfer reactions in both aqueous and non-aqueous solutions. These CNTs have also been used as pastes using different modifiers to form electrodes with high renewability and compatibility.

\subsubsection{Multi-Walled Carbon Nanotube (MWCNT)-Based Detection}

Interesting research related to the use of CNTs for detecting ATM1 can be seen in the work done by Zhao et al. [103]. The magnetic solid-phase extraction technique was used to develop composites containing PEGylated MWCNTs and metallic magnetic nanoparticles (PEG-MWCNTs-MNP). These prototypes were used to isolate and enrich different aflatoxin compounds such as B1, B2, G1, G2, M1, M2 and others. The responses of the sensors were studied using liquid chromatography and Q-Executive high-resolution mass spectroscopy techniques. The prototypes showed very high sensitivity and selectivity towards the tested molecules. High linearity of coefficient of determination $\left(R^{2}\right) \geq 0.995$ was obtained for a detection range of $0.005-0.050 \mu \mathrm{g} / \mathrm{kg}$ of all the chosen compounds. The quantification range was fixed for a range of $0.015-0.15$. The recovery rate was around $81.8-106.4 \%$, along with good repeatability with a range of $2.1-8.5 \%$. The intra-day and inter-day precisions ranged from 2.1 to $8.5 \%$ and from 3.9 to $11.7 \%$, respectively. The tested samples were pre-treated with acetonitrile, followed by transferring them for the adsorption process on PEG-MWCNTs-MNP via employing vortex process. The prototypes were capable of detecting thirteen different types of mycotoxins while analyzing twenty milk samples. The ATM1 was detected within a range from $0.026 \mu \mathrm{g} / \mathrm{kg}$ to $0.039 \mu \mathrm{g} / \mathrm{kg}$.

As a variant to ATM1, aflatoxin B1 (AFB1) is also detected, a pre-metabolized version of ATM1. For example, Singh et al. [104] showed the use of functionalized MWCNTs to detect aflatoxins. The functionalization of the MWCNTs was done using the carboxyl $(-\mathrm{CHO})$ group. The sensing surfaces of the prototypes were successful in functionalizing with monoclonal AFB1 antibodies to detect these molecules. The functionalization of the MWCNTs was done using a mixture formed with hydrocarbon as a source and ferrocene and toluene as catalysts. The prototypes were formed by electrophoretic deposition of MWCNTs on indium tin oxide (ITO) glass substrates. The DC voltage during the electrophoretic deposition was kept to a constant value. Figure 1 [104] illustrates the experimental process carried out with the MWCNT/ITO-based electrodes. The anode and cathode used for this system were ITO glass and platinum foil, respectively. The electrochemical impedance spectroscopy (EIS) technique was used to detect the changes in the responses of these immunosensors. The immobilization process was done using an anti- $\mathrm{AFB}_{1}$ solution, where its amide $\left(-\mathrm{NH}_{2}\right)$ group formed a covalent bond with the $-\mathrm{COOH}$ terminal of MWCNTs. The immobilized electrodes were stored at a temperature of $4{ }^{\circ} \mathrm{C}$ prior to and after use. The sensors had a high sensitivity of $95.2 \mu \mathrm{A} . \mathrm{mL} / \mathrm{ng}^{-1} . \mathrm{cm}^{-2}$, limit of detection (LOD) of $0.08 \mathrm{ng} / \mathrm{mL}$ and linear range of $0.25-1.375 \mathrm{ng} / \mathrm{mL}$. The association constant value of $0.0915 \mathrm{ng} \mathrm{mL}^{-1}$ indicated their high affinity towards the detected molecule.

Another use of MWCNTs for forming nanocomposite-based sensors to detect aflatoxin molecules can be seen in [105]. Here, electrochemical immunosensors for detecting AFB1 molecules were fabricated using palladium (Pd)-gold (Au) nanoparticle-based electrodes that were being supported by poly (diallyl dimethylammonium chloride) (PDDA)/MWCNT-based nanocomposites. Figure 2 [105] shows the schematic illustration of the preparation of an MWCNTs/PDDA/Pd-Au nanocomposite-based electrochemical immunosensor. The Pd-Au nanoparticles were initially synthesized using a dropping and stirring process. This was followed by forming the CNTs-PDDA nanocomposites by treating CNTs with acid and then PDDA aqueous solutions. The resultant suspensions were subjected to centrifugation and sonication processes. The gold electrodes were polished and washed with alumina slurry, followed by distilled water and ethanol. This was followed by dropping samples of CNTs/PDDA/Pd-Au on the surface of the gold electrodes, followed by the evaporation process of the solvent. The experimental samples were prepared using an extraction process, where the samples were shaken, centrifuged, filtered and diluted to obtain the final product. The prototypes showed a high sensitivity 
for a range from $0.05 \mathrm{ng} / \mathrm{mL}$ to $25 \mathrm{ng} / \mathrm{mL}$, along with an LOD of $0.03 \mathrm{ng} / \mathrm{mL}$. The standard deviation was $3 \sigma$, where $\sigma$ is the standard deviation of the blank solution with $n=10$. $A R^{2}$ value of 0.9933 was obtained with the peak current in $\mu \mathrm{A}$ decreased with respect to the increase in concentrations of AFB1 samples.

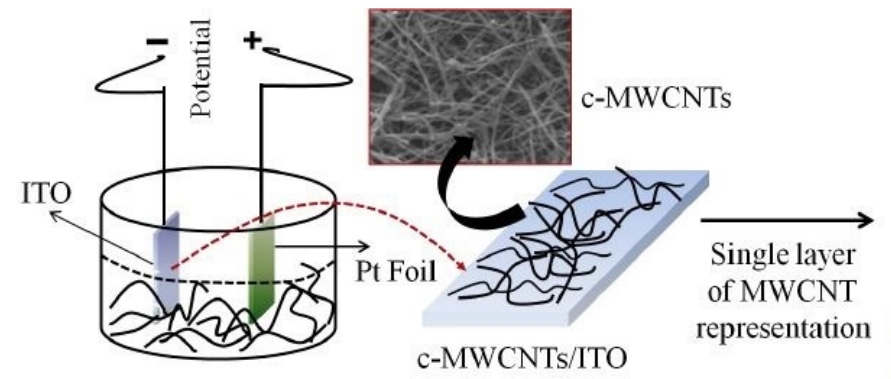

Electrophoretic deposition

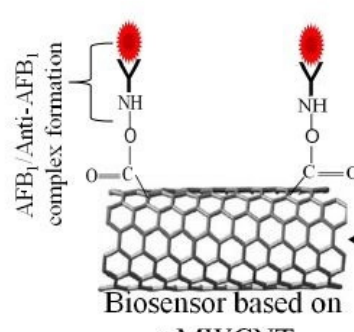

c-MWCNT
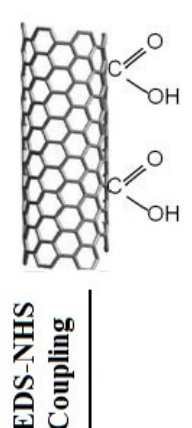

Figure 1. Schematic diagram of the experimental process of detecting AFB1 molecules using carboxyl group functionalized-MWCNTs [104]. Reproduced from Singh, C., Srivastava, S., Ali, M.A., Gupta, T.K., Sumana, G., Srivastava, A., Mathur, R.B. and Malhotra, B.D., 2013. Carboxylated multiwalled carbon nanotubes based biosensor for aflatoxin detection. Sensors and Actuators B: Chemical, 185, pp. 258-264.
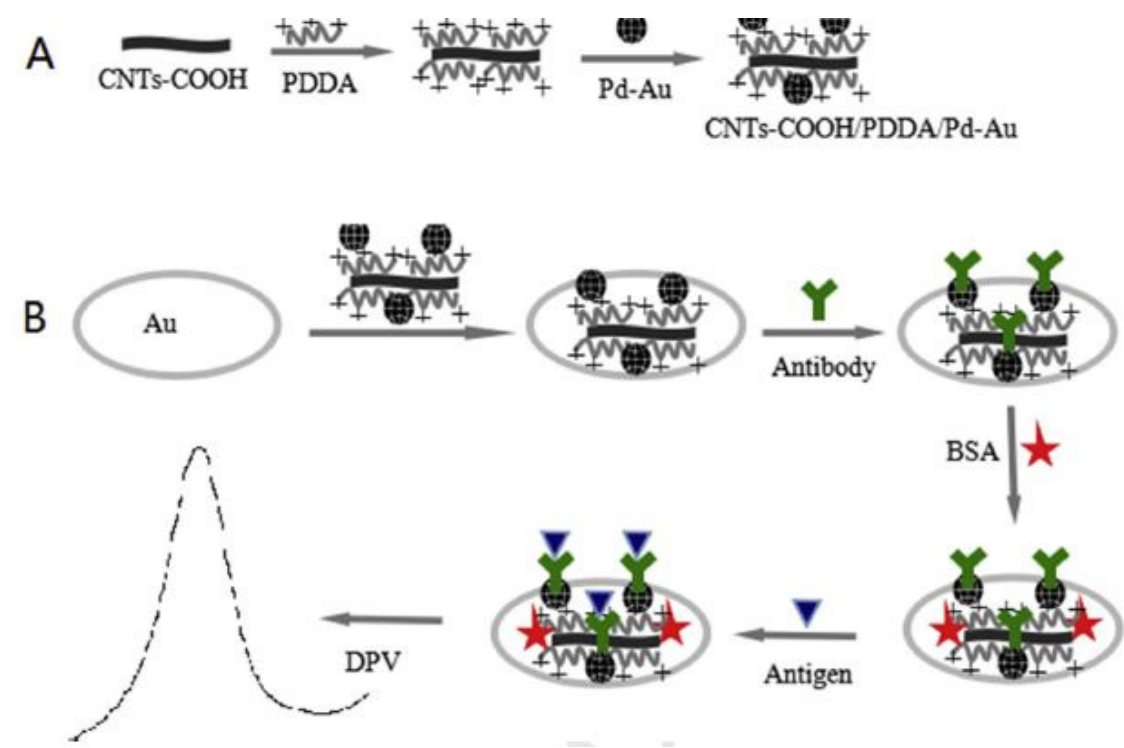

Figure 2. Schematic diagram of the fabrication process of the MWCNTs/PDDA/Pu-Au nanocomposite-based electrochemical immunosensor [105]. (A) first part of process, (B) second part of process. Reproduced from Zhang, S., Shen, Y., Shen, G., Wang, S., Shen, G. and Yu, R., 2016. Electrochemical immunosensor based on Pd-Au nanoparticles supported on functionalized PDDA-MWCNT nanocomposites for aflatoxin B1 detection. Analytical biochemistry, 494, pp. 10-15. 
Another interesting work related to using MWCNT-based immunosensors for the detection of aflatoxin molecules can be seen in [106]. Simultaneous detection of AFB1 and zearalenone $(\mathrm{ZON})$ molecules was done using magnetic nanoparticles formulated using amino-modified MWCNTs. The advantages of this proposed work included a convenient and time-saving approach and the fast, efficient and enhanced response of the sensors. The magnetic properties were induced on the $-\mathrm{NH}_{2}$-functionalized MWCNTs by filling the nanotubes with $\mathrm{Fe}_{3} \mathrm{O}_{4}$ nanoparticles. This was done by treating the nanotubes with ammonium iron sulfate hexahydrate solutions. The mixture was then optimized in terms of $\mathrm{pH}$ values, followed by executing filtration, washing and drying processes. Certain processes such as magnetic solid-phase extraction and high-performance liquid chromatography were used to detect the changes happening in the presence of the two molecules. The influence of other solid-phase extraction parameters such as solution $\mathrm{pH}$, salt addition, temperature, desorption conditions and extraction time was also tested. The sensors showed an excellent response in green analysis, having a score of 89 in analytic eco-scale evaluation. The recovery and relative standard deviation (RSD) ranges of these sensors were 88.8-96\% and 2.1-2.8\%, respectively. The LOD for AFB1 and ZON molecules were $0.15 \mathrm{ng} / \mathrm{g}$ and $0.24 \mathrm{ng} / \mathrm{g}$, respectively, with a $\mathrm{R}^{2}$ value of $>0.999$ for both the molecules. The limit of quantification (LOQ) values for AFB1 and ZON molecules were $0.52 \mathrm{ng} / \mathrm{g}$ and $0.83 \mathrm{ng} / \mathrm{g}$, respectively.

Costa et al. [107] showed a similar work regarding the detection of AFB1 molecules using cysteine-modified gold electrode-immobilized MWCNTs. Label-free electrochemical sensors were fabricated for the detection of carcinogenic AFB1 molecules in pictogram levels. The presence of the MWCNTs assisted in the enhancement of the electrical properties in terms of sensitivity and working range. The gold electrodes of the sensors were initially modified using a self-assembled cysteine layer, followed by covalent bonding of carboxylfunctionalized MWCNTs to the self-assembled layer. With an initial polish using $\alpha-\mathrm{Al}_{2} \mathrm{O}_{3}$ and an ultrasonication bath, the modification was done to create the self-assembled layer. Drop-casting of the carbonyl-MWCNT-diluted solutions was done on the electrodes, followed by an incubation bath for $50 \mathrm{~min}$ at a temperature of $25{ }^{\circ} \mathrm{C}$. Finally, tethering of antibodies was done against AFB1 molecules. This was carried out by drop-casting the EDC:NHS diluted solution at a ratio of 1:1 over the activated platform. The tested AFB1 concentrations included 0.1, 1.0, 3.0, 6.0, 9.0, 11.0, 15.0 and $20.0 \mathrm{pg} / \mathrm{g}$. The charge-transfer resistance changed for a range between $6.97 \mathrm{k} \Omega$ and $84.33 \mathrm{k} \Omega$ for the lowest and highest concentrations, respectively. The LOD of these sensors was $0.79 \mathrm{pg} / \mathrm{g}$, while the linear response was from $0.1 \mathrm{pg} / \mathrm{g}$ to $20 \mathrm{pg} / \mathrm{g}$. Reproducibility in the results of around $5 \%$ was obtained for these portable, label-free sensors.

One of the recent works elucidating the use of MWCNTs for the detection of aflatoxins in milk can be seen in [108]. Polyethyleneimine (PEI) was used as a solid-phase extraction adsorbent to functionalize the magnetic CNTs. Magnetic substrates and epoxy-containing silane agents as linkers were employed for the modification of polyethyleneimine. MWCNTs were used as the conductive material, which was functionalized with iron oxide $\left(\mathrm{Fe}_{3} \mathrm{O}_{4}\right)$ molecules to induce magnetic properties in the CNTs. This was followed by two more modifications with PEI and glymo to obtain a final product of glymo@ $\mathrm{Fe}_{3} \mathrm{O}_{4} \mathrm{MWCNTs}$. The analysis was carried out using magnetic adsorbents integrated with reverse phase and anion exchange interaction sites. The capability of these sensors was validated through different analytic methods in terms of linear range, absolute recovery, matrix effect and precision. The experimental process consisted of testing ten different mycotoxins in milk, having the range of adsorption capacities between $4.9 \mathrm{mg} / \mathrm{g}$ and $10.2 \mathrm{mg} / \mathrm{g}$. The adsorption and desorption processes were completed within $3 \mathrm{~min}$ and $2 \mathrm{~min}$, respectively. The recovery rates increased with the increase in the amount of MWCNTs but were consistent with the variation in the adsorption capacities. The correlation coefficients obtained ranged between 0.9108 and 0.9981 . The standard deviation and LOD ranges were $2.4 \%$ to $6.5 \%$ and $0.003 \mu \mathrm{g} / \mathrm{kg}$ to $0.334 \mu \mathrm{g} / \mathrm{kg}$, respectively. The sensors also had a high recovery range from $88.3 \%$ to $103.5 \%$. 


\subsubsection{Single-Walled Carbon Nanotube (SWCNT)-Based Detection}

Like MWCNTs, SWCNTs have also been used to detect ATM1 compounds in milk [109]. Flexible prototypes having dispense-printed electrodes were formed where functionalized SWCNTs were coated with antibodies to increase their selectivity and sensitivity. The advantages of these sensors were low fabrication cost, easy handling and a high level of customization. Figure 3 [109] shows the schematic diagram of the fabrication process of these functionalized SWCNT-based biosensors. These prototypes were formed on PET substrates having a thickness of 125 microns. The printing process was followed by curing them at $120^{\circ} \mathrm{C}$ for $15 \mathrm{~min}$ to harden the ink.

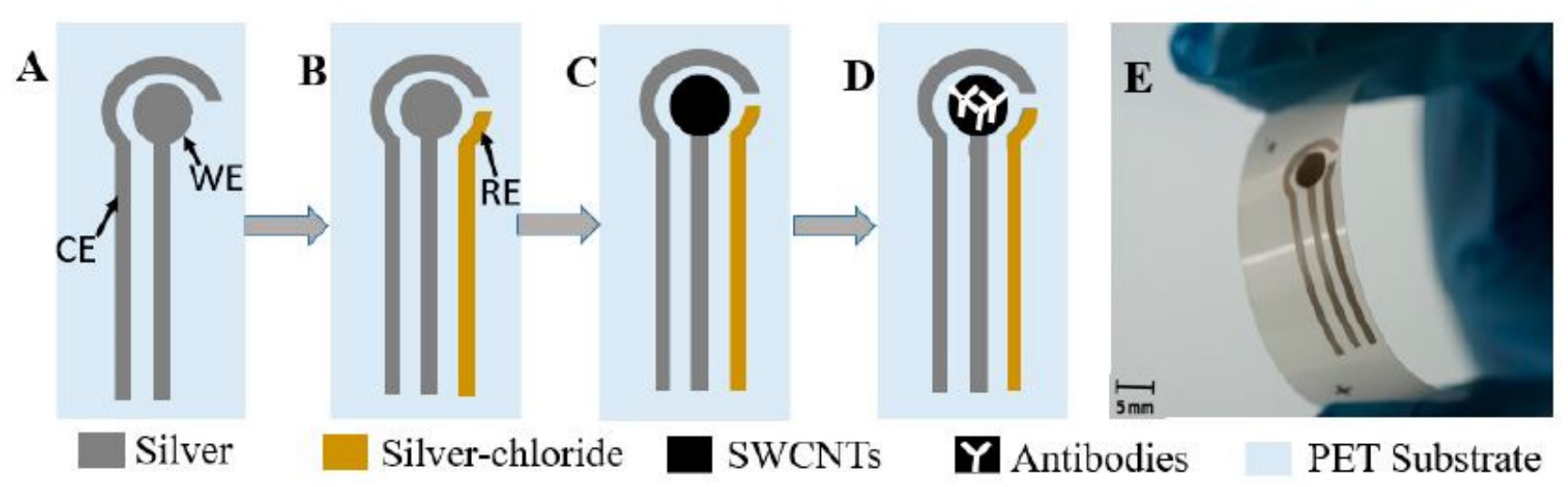

Figure 3. Schematic diagram of the fabrication process of SWCNT/PET-based biosensors [109]. (A) printing working electrode (WE) and counter electrode (CE), (B) printing WE with AgCl by alignment, (C) spray depositing single-walled carbon nanotubes (SWCNTs), (D) immobilization of antibody, and (E) final biosensor. Reproduced from Abera, B.D., Falco, A., Ibba, P., Cantarella, G., Petti, L. and Lugli, P., 2019. Development of flexible dispense-printed electrochemical immunosensor for aflatoxin M1 detection in milk. Sensors, 19(18), p. 3912.

The final step included the spray-coating of the SWCNTs on top of the electrodes via a spray deposition unit and a shadow mask. The cyclic voltammetry (CV) technique was associated with the prototypes to detect the output with respect to the corresponding ATM1 compounds. The working principle is based on a three-electrode system, with silver paste printed with working and counter electrodes and $\mathrm{Ag} / \mathrm{AgCl}$ being the reference electrodes. The immobilization process was done using the drop-casting technique, where secondary antibody solutions were used to treat the working electrode. Prior to the sample testing, the milk was defatted by centrifugation process at a speed, duration and temperature of $6000 \mathrm{rpm}, 15 \mathrm{~min}$ and $4{ }^{\circ} \mathrm{C}$, respectively. The LOD of the sensors was $0.025 \mu \mathrm{g} / \mathrm{L}$. Both the functionalized and un-functionalized electrodes had the same working range between $0.01 \mu \mathrm{g} / \mathrm{L}$ and $1 \mu \mathrm{g} / \mathrm{L}$.

One of the interesting works highlighting the conjugation of SWCNTs with nanoparticles can be shown in [110], where the electrodes were formed using SWCNTs and gold nanoparticles (Au NPs) in chitosan. The immobilization of the sensing area was done using tyrosinase enzymes that showed a reversible behavior. The SWCNTs were treated with different solutions such as nitric acid, sulphuric acid and chitosan to form homogeneous solutions. The biosensitive part of the prototypes was prepared by treating them with BSA phosphate buffer solutions, distilled water and glutaraldehyde solution. Finally, the sensing surface of the screen-printed electrodes was modified using Au NPs that were obtained as pink wine-red solutions. The kinetic studies of these sensors were done at a concentration of $1 \times 10^{-3} \mathrm{M}$. The working range and LOD of the sensors were $1 \times 11^{-11} \mathrm{M}-1 \times 10^{-6} \mathrm{M}$ and $5 \times 10^{-12} \mathrm{M}$, respectively. The sensors showed a two-parameter mismatch inhibition for the composites developed with CNTs and Au NPs. The maximum level of inhabitation by ATM1 on these sensors was $78 \pm 1.0 \%$. When the performance of these sensors was compared to the ones developed using tyrosinase-functionalized screen-printed graphene oxide 
sensors, it was seen that the ones formed using CNTs/Au NPs had a higher sensitivity and correlation coefficient.

The work done by Gan et al. [85] can be exemplified to show the use of SWCNTbased composites for developing electrochemiluminescent immunoassays (ECLIA) for the detection of ATM1 in milk. The working principle of these ELCIA-based sensors was based on two parts, namely the extraction and detection processes. The extraction process was carried out using magnetic graphene, while the detection part was done by nanocomposites formed by mixing antibody-labeled cadmium telluride $(\mathrm{CdTe})$ quantum dots and SWCNTs. The CdTe quantum dots were used as signal tags, which were attached to the primary ATM1 antibodies in the form of nanocomposites. The immobilization of GO was done with $\mathrm{Fe}_{3} \mathrm{O}_{4}$ nanoparticles to develop the magnetic nanocomposites for absorbing the ATM1 compounds. In order to form the conjugates, stirring and ultrasonication processes were deployed after the reaction of SWCNTs with dimethylformamide (DMF) and polydiallyldimethylammonium chloride (PDDA) solutions, respectively. CdTe quantum dots having free surface $-\mathrm{COOH}$ groups were used to form dispersions, followed by reacting them with SWCNTs-PDDA solutions to obtain the final solution having a 1:1 concentration ratio. The labeling of the antibodies was done using a centrifugation process with a speed and duration of $5000 \mathrm{rpm}$ and $10 \mathrm{~min}$, respectively. The adsorption process was done for $\mathrm{pH}$ values ranging between 3.0 and 8.0, where $95 \%$ of the equilibrium process was achieved within $10 \mathrm{~min}$. The sandwich ECLA process was employed for the detection of ATM1 in milk samples. The linear range of the sensors was from $1 \mathrm{pg} / \mathrm{mL}$ to $1 \times 10^{5} \mathrm{pg} / \mathrm{mL}$, along with a LOD of $0.3 \mathrm{pg} / \mathrm{mL}$. The testing was done for ten milk samples, the results of which proved to be more effective than the standard ELISA method. Table 3 shows a comparison between the performances of the CNT-based sensors to detect ATM1 and AFB1 molecules. It is seen that the performances of the prototypes are largely dependent on the type of processed materials being associated with these CNTs.

Table 3. Comparison of the performances of the CNT-based sensors for the detection of ATM1 and AFB1 compounds.

\begin{tabular}{|c|c|c|c|c|c|}
\hline Processed Materials & Fabrication Technique & Detection Analyte & Linear Range & Limit of Detection & Ref. \\
\hline $\begin{array}{c}\mathrm{Fe}_{3} \mathrm{O}_{4}, \mathrm{GO}, \mathrm{CdTe} \\
\text { quantum dots, CNTs }\end{array}$ & $\begin{array}{l}\text { In situ chemical } \\
\text { co-precipitation, } \\
\text { ultrasonication }\end{array}$ & ATM1 & $1.0 \times 10^{5} \mathrm{pg} / \mathrm{mL}$ & $0.3 \mathrm{pg} / \mathrm{mL}$ & [85] \\
\hline $\begin{array}{c}\text { PEG, MWCNTs, } \\
\text { magnetic nanoparticles }\end{array}$ & Centrifugation, stirring & ATM1 & $\mathrm{R}^{2} \geq 0.995$ & $0.005-0.050 \mu \mathrm{g} / \mathrm{kg}$ & [103] \\
\hline $\begin{array}{c}\text { Carboxyl-functionalized } \\
\text { MWCNTs, ITO, } \\
\text { glass substrate }\end{array}$ & $\begin{array}{l}\text { CVD, electrophoretic } \\
\text { deposition }\end{array}$ & ATM1 & $0.25-1.375 \mathrm{ng} \mathrm{mL}^{-1}$ & $0.08 \mathrm{ng} \mathrm{mL}^{-1}$ & [104] \\
\hline $\begin{array}{l}\text { PDDA-MWCNTs, Pd } \\
\text { Au NPs, Pd NPs }\end{array}$ & Centrifugation, stirring & AFB1 & $0.05-25 \mathrm{ng} / \mathrm{L}$ & $0.03 \mathrm{ng} \mathrm{mL}^{-1}$ & [105] \\
\hline $\mathrm{Fe}_{3} \mathrm{O}_{4}, \mathrm{NH}_{2}-\mathrm{MWCNTs}$ & Centrifugation, stirring & AFB1 & $1-100 \mathrm{ng} / \mathrm{g}$ & $0.15 \mathrm{ng} / \mathrm{g}$ & [106] \\
\hline $\begin{array}{c}\text { Carboxyl-functionalized } \\
\text { CNTs, anti-AFB1, } \\
\text { cysteine }\end{array}$ & $\begin{array}{l}\text { Self-assembly, } \\
\text { centrifugation }\end{array}$ & AFB1 & $0.1-20 \mathrm{pg} / \mathrm{g}$ & $0.78 \mathrm{pg} / \mathrm{g}$ & [107] \\
\hline $\mathrm{Fe}_{3} \mathrm{O}_{4}, \mathrm{MWCNTs}, \mathrm{PEI}$ & Centrifugation, stirring & AFB1 & $R^{2}=0.9982-0.9997$ & $\begin{array}{l}0.003 \mu \mathrm{g} / \mathrm{kg}^{-1}- \\
0.442 \mu \mathrm{g} \mathrm{kg}-1\end{array}$ & [108] \\
\hline SWCNTs, mAb, PET & Screen printing & ATM1 & - & $0.02 \mu \mathrm{g} / \mathrm{L}$ & [109] \\
\hline $\begin{array}{l}\text { CNTs, graphene oxide, } \\
\text { Au NPs, tyrosinase }\end{array}$ & Centrifugation, stirring & ATM1 & - & $5 \times 10^{-12} \mathrm{M}$ & [110] \\
\hline
\end{tabular}

\subsection{Graphene-Based Sensing Prototypes}

Graphene has been one of the most widely-used carbon allotropes for developing flexible sensors for a wide range of applications. Due to the enhanced electrical, mechanical and thermal characteristics, graphene in its pure, oxide and composite forms has achieved the required performances. Biomedical sensing applications have also been used to detect biomolecules [111-113] to their high surface-to-volume ratio, excellent electrical conductiv- 
ity and tunable optical properties. This helps the sensors to achieve high sensitivity, low LOD and detection without any chemical mediators [111]. Apart from this, the advantage of the biocompatibility of graphene has led many research groups and industries to develop wearable graphene-based sensors for ubiquitous applications.

\subsubsection{Graphene Oxide-Based Detection}

Jia et al. [112] showed the fabrication and implementation of label-free fluorescent aptasensors to detect AFB1 molecules. The constituents of these sensors included the quaternization of tetra-phenylethene salt (TPE-Z), GO and AFB1 aptamer. The primary advantage of this work includes the single-step operation process compared to the other aptamer used for detecting AFB1 molecules with GO-based sensors. Figure 4 [112] represents the working mechanism of these label-free aptasensors that were used for the detection of AFB1 molecules. The operating principle of these sensors was based on the conformational switch of the AFB1 aptamer from the single-stranded structure to the aptamer complex. This process leads the GO to release the TPE-Z/AFB1 aptamer from its surface. The fluorescence intensity was recorded at a wavelength of $480 \mathrm{~nm}$, having an excitation at $340 \mathrm{~nm}$. The sensitivity values were measured three times for each concentration. The LOD of these devices was $0.25 \mathrm{ng} / \mathrm{mL}$. These sensors showed the capability to selectively detect aflatoxins in certain foods such as milk, corn and rice. Before using these food samples, extraction was done using methanol-water, centrifugation and filtration processes. Finally, the supernatants were taken for analysis purposes. The sensors could detect AFB1 molecules from all three types of food, with the recovery rate ranging between $91 \%$ and $95 \%$.

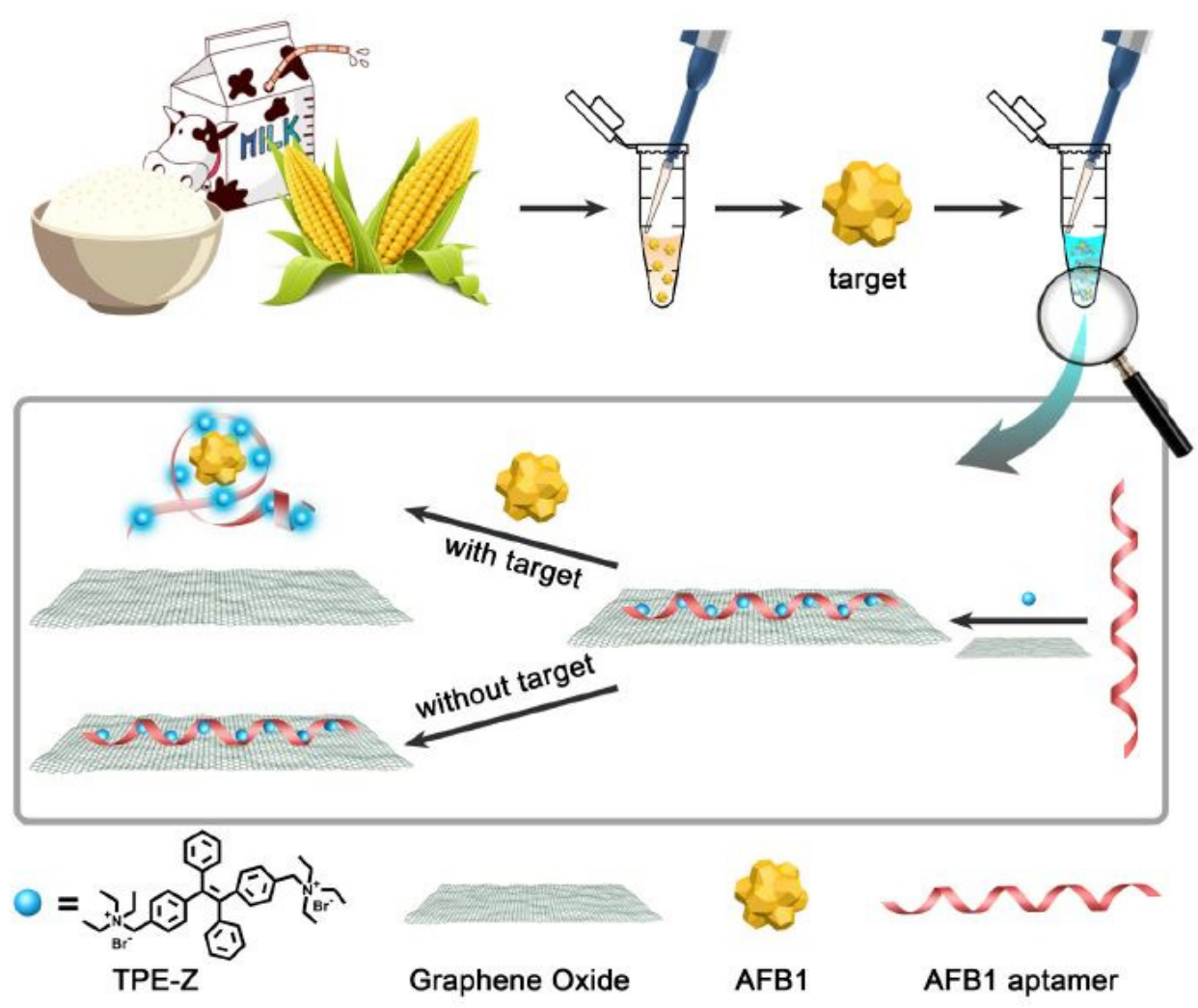

Figure 4. The working mechanism of the TPE-Z/AFB1 aptamer/GO-based devices for the detection of AFB1 molecules in different types of food samples [112]. Reproduced from Jia, Y., Wu, F., Liu, P., Zhou, G., Yu, B., Lou, X. and Xia, F., 2019. A label-free fluorescent aptasensor for the detection of Aflatoxin B1 in food samples using AIEgens and graphene oxide. Talanta, 198, pp. 71-77.

Guo et al. [113] also showed the use of GO to develop an aptasensor to detect ATM1 in milk products. The GO particles also quenched on the fluorescence principle, where 
it was done on an aptamer labeled carboxyfluorescein while protecting it from nuclease cleavage. The presence of ATM1 formed a complex, which resulted in its detachment from the surface of the GO and causing aptamer cleavage by DNase I. The GO binding with the ss-DNA via $\pi$-stacking interactions helped with the high distance-dependent fluorescence quenching performance. This was followed by the detachment of target AFM1, leading to a new cycle. The testing was done with infant milk powder samples. The samples were spiked with AFM1 molecules at four concentrations of $0,1.5,2.5$ and $5 \mu \mathrm{g} / \mathrm{kg}$.

After the weight of the samples was measured carefully, the extraction process was carried out, and the supernatant was concentrated under a nitrogen stream. Finally, the residues were mixed with methanol solution and used for fluorescence signal amplification experiments. The linear response and LOD of the sensors were $0.2-10 \mu \mathrm{g} / \mathrm{kg}$ and $0.05 \mu \mathrm{g} / \mathrm{kg}$, respectively. The recovery rate for the chosen spiked concentrations was between $98 \%$ and $126 \%$, with RSD values of 0.06 and 0.42 . The prototypes also showed high sensitivity and selectivity towards the AFM1 molecule without the presence of any interference. Another research by Zhang et al. [114] showed the use of fluorescence quenching immunoassay and graphene-based composites. The assays were formed using a monoclonal antibody $(\mathrm{mAb})$-functionalized $\mathrm{Fe}_{3} \mathrm{O}_{4}$-decorated $\mathrm{GO}$ that acted as a capture probe and energy acceptor. These assays were combined with tetramethylrhodamine cadaverine-labeled AFB1 molecules. The advantages of these sensors included their singlestep preparation and detection process, low quantitative detection limit, low cost of the sensors, precise quantitative analysis and the entire process being completed within $10 \mathrm{~min}$. The magnetic rGO was formed by processing different solutions such as iron chloride and ferric chloride, forming dispersions with GO solutions. These dispersions were processed using techniques of ultrasonication and centrifugation to obtain the final product. The sensors were tested with ATM1 concentrations ranging from $0.01 \mathrm{ng} / \mathrm{L}$ and $2 \mathrm{ng} / \mathrm{L}$ to obtain recovery rates ranging between $94.4 \%$ and $104.5 \%$. High linearity of $R^{2}=0.999$ was also obtained with these sensors' performance compared to a commercialized enzyme-linked immunosorbent assay (ELISA) kit. With a high reproducibility of the results, the values of coefficients of variation were under $6.2 \%$. The visual and quantitative LOD were $50 \mathrm{ng} / \mathrm{L}$ and $3.8 \mathrm{ng} / \mathrm{L}$, respectively.

An example showing the use of both graphene and crystalline quantum dots for forming fluorescence assays for the detection of aflatoxin molecules can be seen in the work done by Lu et al. [115]. GO was linked with CdTe quantum dots via ligand exchange as a quenching process to determine the performance of the fluorescence-based devices. The GO was synthesized using Hummers' method, followed by mixing it with hydrogen peroxide to form GO suspensions. The CdTe quantum dots were formed by processing trisodium citrate dehydrate and cadmium chloride solutions using stirring, followed by heating them inside a Teflon-lined stainless autoclave. The temperature and duration were maintained at $180{ }^{\circ} \mathrm{C}$ and $35 \mathrm{~min}$, respectively. Finally, the samples were washed and centrifuged to obtain the pigmented layers and remove the residual chemicals. Finally, the individual conductive materials were conjugated with the aptamer and centrifuged again, both the composites being required to detect AFB1 molecules. The prototypes showed good sensitivity and selectivity and had a wide dynamic range of 3.2-320 nM. While the LOD of the sensors was $1 \mathrm{mM}$, they achieved high linearity with $\mathrm{R}^{2}=0.998$. They showed high selectivity towards the aflatoxin molecules in the presence of other molecules such as fumonisin B1, ochratoxin A, zearalenone and deoxynivalenol. The response of these sensors in terms of fluorescence intensity with the corresponding enhancement of the AFB1 concentration ranged from $1.6 \mathrm{nM}$ to $160 \mu \mathrm{M}$.

Apart from these quantum dots and nanosheets, graphene oxide (GO) has been largely preferred to form the prototypes to detect aflatoxin molecules. The primary reason behind this is its ability to form homogeneous dispersions, necessary for forming these electrochemical sensors. One such work can be highlighted in [116], where the prototypes were formed by functionalization of luminol on Ag NP-decorated GO. Bipolar electrode arrays were formed that operated on the visual ECLIA biosensing technique. The Au NPs 
were coated with magnetic $\mathrm{Fe}_{3} \mathrm{O}_{4}$ nanoparticles before their immobilization with thiolated ATM1 aptamer. Figure 5 [116] shows the schematic diagram of the immobilization of the antibody with these GO nanocomposite-based sensors. The operating mechanism of these sensors depended on the $\pi-\pi$ interactions of the nanocomposites with the unpaired bases of the immobilized aptamer. The composites consisting of GO, luminol and Ag NPs were synthesized using the one-pot method. Before the experimental process, the anodic poles were modified with the nanocomposites on the gold bipolar electrode arrays. The Ag NPs assisted in the catalysis of the ECL process on the sensing surface of the prototypes. The optimal conditions were achieved using a face-centered central composite design, where the aptasensors obtained a linear response for a dynamic range between $5 \mathrm{ng} / \mathrm{mL}$ and $150 \mathrm{ng} / \mathrm{mL}$. This range increased to $10-200 \mathrm{ng} / \mathrm{mL}$ when smartphones were embedded with the sensors for using them for point-to-point services. The LOD of the sensors without and with the smartphones was $0.01 \mathrm{ng} / \mathrm{mL}$ and $0.05 \mathrm{ng} / \mathrm{mL}$, respectively. A reliability reproducibility was also obtained with an RSD of $2.3 \%$.

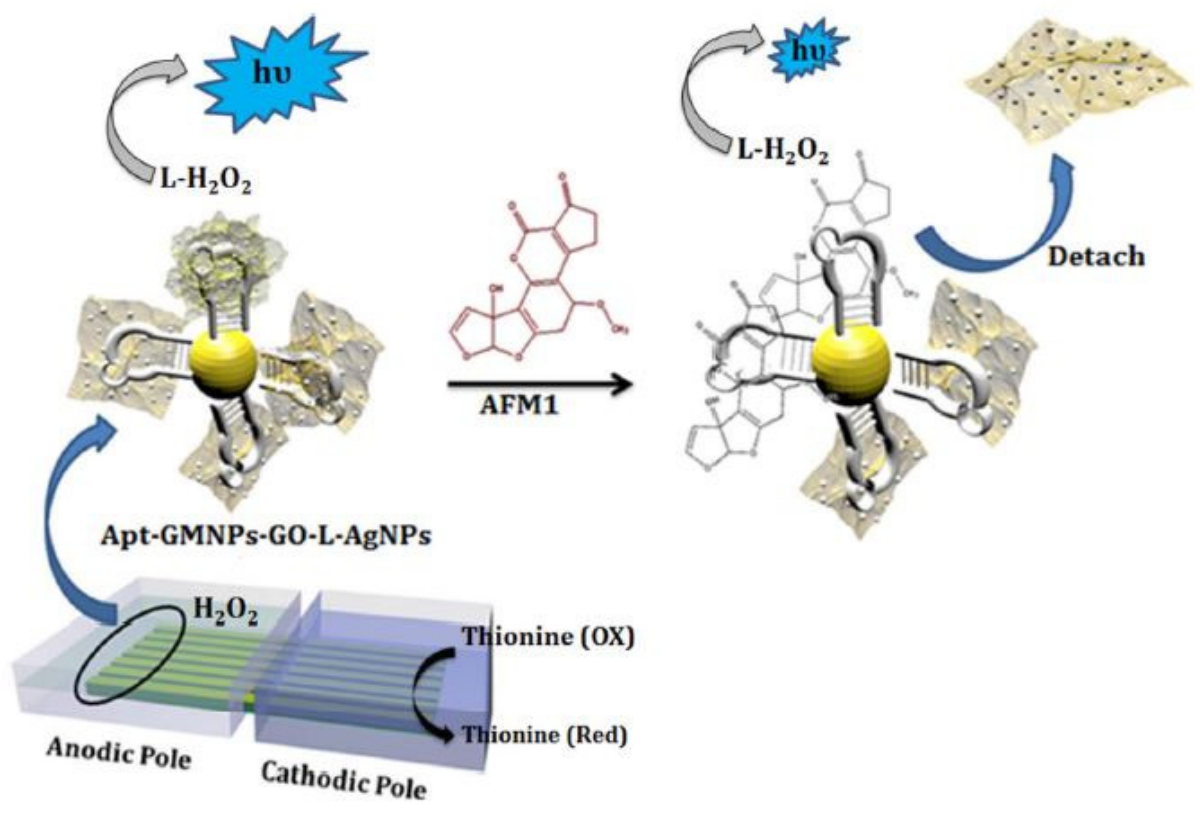

Figure 5. Representation of the immobilization process of the ATM1-based antibody with the luminol-functionalized Ag NP decorated GO [116]. Reproduced from Khoshfetrat, S.M., Bagheri, H. and Mehrgardi, M.A., 2018. Visual electrochemiluminescence biosensing of aflatoxin M1 based on luminol-functionalized, silver nanoparticle-decorated graphene oxide. Biosensors and Bioelectronics, 100, pp. 382-388.

Another example showing the use of GO can be shown in [117], where impedimetric sensors were formed using single-stranded Herring sperm DNA (ss-HSDNA) and reduced graphene oxide (rGO) for the detection of AFB1 molecules. These aerogel-labeled prototypes were quantified on rotating disk electrodes, where the ss-HSDNA and rGO were conjugated to operate with the CV technique. The rGO aerogel was formed using the Hummers and Offman method with a slight change in the modification of the use of Milli-Q water for $30 \mathrm{~min}$. The GO suspensions were then treated with hydrazine for reducing them, followed by soaking and drying them to obtain the final product. The modification of the electrodes was done by drop-casting on glassy carbon rotating disk electrodes having a diameter of $3.0 \pm 1.0 \mathrm{~mm}$. These glassy substrates were then polished with alumina and washed with purified water before their experimental uses. The consideration of the presence of $\mathrm{FCCH}_{2} \mathrm{OH}$ as the redox mediator was done to detect the hydrodynamic diffusion effect of the ss-HSDNA/rGO-based devices. Two techniques, namely electro-redox mediators and the hydrodynamic effect, were considered to obtain three different charge values of $825 \mathrm{~mA}, 615 \mathrm{~mA}$ and $550 \mathrm{~mA}$. These anodic current values were obtained at a 
scan rate of $50 \mathrm{mV} / \mathrm{s}$. The rotating speed of the disk electrodes ranged from $500 \mathrm{rpm}$ to $4000 \mathrm{rpm}$. The linear range of the sensors was from $1 \times 10^{-1} \mathrm{~g} / \mathrm{mL}$ to $7 \times 10^{-8} \mathrm{~g} / \mathrm{mL}$, with an LOD of $0.04 \mathrm{ng} / \mathrm{mL}$.

Jiang et al. [118] showed an interesting work where the graphene-based sensors were used to detect nine mycotoxins in milk. The sensors were formed using rGO and gold nanoparticles. Two different processes, namely solid-phase extraction coupling of ultrahigh-performance liquid chromatography-tandem mass spectrometry, were used as the detection mechanisms. The rGO/gold nanoparticles composite was formed using stirring, centrifugation and annealing processes. Before their use, the synthesized composites were stored at a temperature of $-20^{\circ} \mathrm{C}$ and cryodesiccated. The experiments were conducted with milk to determine these nine types of mycotoxins that included the AFB1 and ATM1 compounds. The milk products were spiked with each of these nine compounds for 1,20 and $100 \mathrm{ng} / \mathrm{mL}$ concentrations. A total of sixty milk samples were tested during the entire experimental process. The testing samples were prepared by using three different types of solutions. The loading and washing solutions included $2 \%$ acetonitrile/formic acid and $5 \%$ methanol in water, respectively. These graphene-based sensors showed excellent analytical response with a high sensitivity of $0.02-0.18 \mathrm{ng} / \mathrm{mL}$, recovery of $70.2-111.2 \%$ and a precision of $2-14.9 \%$. The linearity of the sensors was satisfactory with $R^{2} \geq 0.992$. The LOD and LOQ values of the sensors were 3 and 10, respectively.

Mo et al. [119] worked on the development and implementation of AFB1 biosensors based on porous anodized alumina (PAA) membranes. These membranes were modified using GO and AFB1 aptamers. Figure 6 [119] shows the schematic diagram of the working mechanism of these biosensors. After being synthesized using Hummers' method, the $\mathrm{GO}$ was processed using various chemicals to form GO hydrosol. These hydrosols were centrifuged, washed, dialyzed and finally stored. The modification of the PAA membranes was done by treating them with 5\% 3-aminopropoyltrimethoxysilane solution for $12 \mathrm{~h}$.

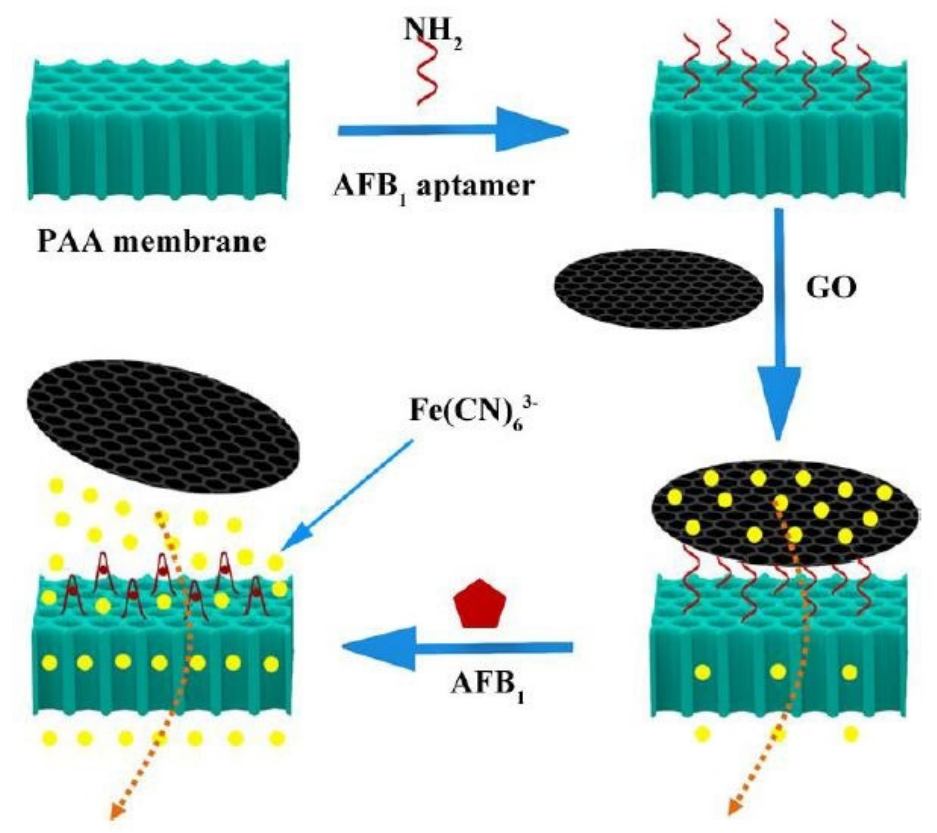

Figure 6. Illustration of the working mechanism of the GO-modified PPA membranes for the detection of AFB1 molecules [119]. Reproduced from Mo, R., He, L., Yan, X., Su, T., Zhou, C., Wang, Z., Hong, P., Sun, S. and Li, C., 2018. A novel aflatoxin B1 biosensor based on a porous anodized alumina membrane modified with graphene oxide and an aflatoxin B1 aptamer. Electrochemistry Communications, 95, pp. 9-13.

Finally, they were again washed and dried at $110^{\circ} \mathrm{C}$ for an hour to form a silane layer. This was followed by the immobilization process, which took place inside a customized 
electrocatalytic cell. The GO was attached to the aptamer via $\pi-\pi$ stacking, which led to increased negative charge of the nanochannels. This change in charge density and steric hindrance leads to the flux of ferricyanide ions through the nanochannels, thus increasing overall current. These devices were selective towards three molecules, namely ochratoxin, aflatoxin G1 and AFB1. They were tested for a concentration of $10 \mathrm{ng} / \mathrm{mL}$ for AFB1 by immersing the sensors inside the samples for $90 \mathrm{~min}$ and analyzing the current change with respect to time. The experimental results showed that the current increased properly with respect to the concentration of AFB1 molecules. The sensors had a linear range of $1-20 \mathrm{ng} / \mathrm{mL}$ and a LOD of $0.13 \mathrm{ng} / \mathrm{mL}$.

\subsubsection{Other Types of Graphene Nanostructure-Based Detection}

For the detection of ATM1, one of the interesting examples can be given by highlighting the work done by Shadjou et al. [120]. Graphene quantum dots (GQDs) were employed in conjugation with silver nanoparticles (Ag NPs) to form the electrochemical sensors. These sensors also contained a member of cyclic oligosaccharides, $\alpha$-cyclodextrin, which increased the sensitivity of these multi-layered films. These nanocomposite-based sensors were formed on glassy carbon electrodes due to their high surface area available for detection purposes. The GQDs were formed by dispersing carbonized products into alkaline solutions by pyrolyzing citric acid. The samples were then treated with sodium hydroxide and were stirred to obtain the final result. These GQDs were electrodeposited on the surface of the glassy carbon electrodes with a potential and scan rate of $0-1 \mathrm{~V}$ and $100 \mathrm{mV} / \mathrm{s}$, respectively. The CV technique was conducted during the electrodeposition process to analyze, optimize and obtain thin-film electrodes. These samples were then used for the electro-polymerization of $\alpha-C D$ using the $C V$ technique again with a voltage sweep between $-1 \mathrm{~V}$ and $1 \mathrm{~V}$ and a scan rate of $100 \mathrm{mV} / \mathrm{s}$ for ten cycles. The final step included the electrodeposition of Ag NPs on the surface of the electrodes using similar parameters as in the earlier step. The milk samples used for experimental purposes consisted of local and pasteurized milk. The linear range of these sensors was from $0.015 \mathrm{mM}$ to $25 \mathrm{mM}$, with an LOQ of $2 \mu \mathrm{M}$. The capability of these sensors was validated by analyzing their performances with respect to solution $\mathrm{pH}$, potential scan rate, reproducibility and stability.

Another work related to the use of GQDs can be seen in [121], where electroluminescence (ECL) aptasensors were developed for the detection of AFB1 molecules. The GQDs were used to form nanocomposites that consisted of gold nanorods, poly (indole6-carboxylic acid) and flower-gold. The ECL aptasensors were formed by using the potentiostatic method on glassy carbon electrodes. The final nanocomposite solution was incubated with different concentrations of AFB1 molecules at a temperature of $37^{\circ} \mathrm{C}$ for $80 \mathrm{~min}$. The characterization of the nanocomposites was done using the EIS technique, while the experimental process included the study of ECL intensity. The nanocomposites having a core-shell structure had certain advantages such as high electrical conductivity and superior luminescent performance. The immobilization of gold nanorods was done with an AFB1 aptamer chain to enhance the overall selectivity and sensitivity. AFB1 standard solutions were formed by adding $1 \mathrm{nM}, 2 \mathrm{nM}$ and $5 \mathrm{nM}$ of AFB1 molecules to the actual samples. The recovery values of these sensors were $97.1-111.8 \%$, which was quite close to the recovery values of the standardized high-performance liquid chromatography fluorescence (HPLC-FL) (90.7-114.7\%) process. The prototypes had a wide dynamic range from 0.01 to $100 \mathrm{ng} / \mathrm{mL}$ with an LOD of $0.00375 \mathrm{ng} / \mathrm{mL}$. Other attributes of the sensors were high stability and reproducibility of the responses, high accuracy and high reliability for real samples analysis.

Another research showing the use of graphene nanostructures for developing flexible prototypes for the detection of aflatoxin molecules can be seen in [122]. The sensors were formed with graphene nanosheets on ITO-coated substrates. The advantages of these sensors are their rapid fabrication process, simple operating principle and low cost. The ITO coating was done on glass substrates with dimensions of $20 \mathrm{~mm} \times 10 \mathrm{~mm} \times 1.1 \mathrm{~m}$. Before and after the coating process, they were cleaned via the sonication process and dried using 
nitrogen gas. This was followed by electrochemical deposition of rGO nanosheets, followed by electrochemical deposition of gold nanodots using aqueous solutions. The potentials used during the first and second electrochemical deposition processes were $-1.6 \mathrm{~V}$ and $-0.9 \mathrm{~V}$, respectively. The next step included the immobilization of these prototypes with the AFB1 antibody with the self-assembly technique. The duration and temperature were fixed at $6 \mathrm{~h}$ and $4{ }^{\circ} \mathrm{C}$, respectively. The $\mathrm{CV}$ technique was used as the detection technique to test the food samples spiked with AFB1 molecules. The spiking was done with three different concentrations, namely $10 \mathrm{ng} / \mathrm{mL}, 50 \mathrm{ng} / \mathrm{mL}$ and $100 \mathrm{ng} / \mathrm{mL}$. These electrochemical sensors were used to detect AFB1 molecules with a LOD of $6.9 \mathrm{pg} / \mathrm{mL}$. The sensors retained around $96 \%$ of their original response while experimenting with $50 \mathrm{ng} / \mathrm{mL}$ concentration for ten days.

Another variation in the graphene structure can be shown in Tezeji et al. [123]. $\beta$-cyclodextrin was developed using a facile one-pot green synthesis method and was subsequently decorated using graphene nanohybrids. Some of the advantages of these sensors were high specific surface area and high supramolecular recognition and enrichment capability. The functionalization of the $\beta$-cyclodextrin was carried out using hydrothermal reaction and reduction processes. After $\mathrm{GO}$ was synthesized from graphene nanosheets using the modified Hummers method, they were self-assembled onto $\beta$-cyclodextrin. The one-pot hydrothermal process included GO dispersions on $\beta$-CD solutions, followed by ultrasonication for $15 \mathrm{~min}$. Finally, the samples were heated, washed with deionized water and frozen at $-50{ }^{\circ} \mathrm{C}$ to form porous structures. The sensors could detect different types of aflatoxin molecules such as B1, B2, G1 and G2. The LOD and linear range of these sensors were $7.5-30 \mathrm{ng} / \mathrm{kg}$ and $25-100 \mathrm{ng} / \mathrm{kg}$, respectively. The LOQ according to the signal-to-noise ratio was 10 . The effects of other parameters such as $\mathrm{pH}$, adsorbent amount, sample loading flow rate, ionic strength and reusability of the sensors were also studied. The sensors also showed an excellent recovery rate with a range from 90.5 to $105 \%$, with high accuracy for three concentration levels of $250 \mathrm{ng} / \mathrm{kg}, 1000 \mathrm{ng} / \mathrm{kg}$ and $10,000 \mathrm{ng} / \mathrm{kg}$. The relative standard deviation was less than $6.1 \%$ when the testing was done five times in a single day with an interval of one hour. Table 4 showcases a comparative study for the performances of the graphene-based sensors for the detection of ATM1 and AFB1 compounds.

Table 4. Comparative study of the performances of the graphene-based sensors for the detection of ATM1 and AFB1 compounds.

\begin{tabular}{|c|c|c|c|c|c|}
\hline Processed Materials & Fabrication Technique & Detection Analyte & Linear Range & Limit of Detection & Ref. \\
\hline GO, AFB1 aptamer, TPE-Z & Stirring & AFB1 & $0-3 \mathrm{ng} / \mathrm{mL}$ & $0.25 \mathrm{ng} / \mathrm{mL}$ & [112] \\
\hline GO, ATM1 aptamer & Centrifugation & ATM1 & $0.2-10 \mu \mathrm{g} / \mathrm{kg}$ & $0.05 \mu \mathrm{g} / \mathrm{kg}$ & [113] \\
\hline $\mathrm{mAb}, \mathrm{Fe}_{3} \mathrm{O}_{4}, \mathrm{rGO}$ & $\begin{array}{l}\text { Ultrasonication, } \\
\text { centrifugation }\end{array}$ & AFB1 & - & $\begin{array}{l}50 \mathrm{ng} / \mathrm{L} \text { and } \\
3.8 \mathrm{ng} / \mathrm{L}\end{array}$ & [114] \\
\hline CdTe quantum dots, GO & $\begin{array}{l}\text { Hummers' method, } \\
\text { stirring, annealing }\end{array}$ & AFB1 & - & $1 \mathrm{nM}$ & [115] \\
\hline $\begin{array}{c}\text { Luminol, } \mathrm{Ag} \text { NPs, GO, } \\
\mathrm{Fe}_{3} \mathrm{O}_{4}\end{array}$ & Self-assembly, stirring & ATM1 & 5-150 ng/mL & $0.01 \mathrm{ng} / \mathrm{mL}$ & [116] \\
\hline rGO, ss-DNA & $\begin{array}{l}\text { Hummers and } \\
\text { Offman method }\end{array}$ & AFB1 & $R^{2}=0.996$ & $\begin{array}{c}1 \times 10^{-10_{-}} \\
7 \times 10^{-8} \mathrm{~g} / \mathrm{mL}\end{array}$ & [117] \\
\hline $\begin{array}{c}\alpha \text {-cyclodextrin, GQDs, } \\
\text { Ag NPs }\end{array}$ & Electrodeposition & ATM1 & $0.015 \mathrm{mM}-25 \mathrm{mM}$ & $2 \mu \mathrm{M}$ & [120] \\
\hline $\begin{array}{l}\text { rGO nanosheets, } \mathrm{Au} \\
\text { nanorods, ITO }\end{array}$ & Self-assembly & AFB1 & $\begin{array}{c}100 \\
\mathrm{ng} / \mathrm{mL}-1 \mathrm{pg} / \mathrm{mL}\end{array}$ & $6.9 \mathrm{pg} / \mathrm{mL}$ & [122] \\
\hline
\end{tabular}

\section{Results}

Although a substantial amount of work has been done in detecting aflatoxin biomolecules in milk and other food products, there are still some bottlenecks that need to be addressed. The formation of homogenous dispersions using CNTs is one issue that remains unsolved. Although surfactants have tackled this problem to a certain degree, these compounds generally affect the mechanical integrity of the nanotubes, which eventually affects the 
results. The utilization of these prototypes as point-of-care (POC) devices should be further encouraged to obtain a quick and efficient response regarding the concentration of ATM1 and AFB1 compounds in milk and other food products. In order to generate POC devices, three factors need to be taken into consideration [124-127]. These factors include the use of disposable sensors, amplification of the sensed response via embedded circuitry and the use of open-source software and hardware as the associated electronics. Although the first factor would increase overall cost, it would assist in maintaining a high sensitivity towards the target analyte. The second factor would help in two ways, namely eliminating the unwanted noise and presenting the sensed data in a most easily comprehensible way. The essentiality in using the open-source will guarantee the deployment of standardized procedures used by people who faced a similar situation. It will also help to obtain constructive feedback to improve the quality of the POCs. In the era of 3D printers and laser cutters, open-source hardware is easily available and customizable, assisting in commercializing the sensing systems. Two of the major steps that need to be implemented to obtain a POC device are the fabrication of a lab-on-a-chip sensing system and the replacement of commercially available tools with self-made solutions via open-source resources. An optimization process should be carried out to determine the ideal sample concentration to achieve better responses in terms of the analytical performances of the sensors.

The signal processing part of the electronic circuitry should include microcontrollerbased platforms such as Arduino or Raspberry Pi to develop low-cost devices that are easily available to the users. Similarly, the readout part should have simple digital scales for users who have little or no prior experience in electrical engineering. Due to the requirement of microelectronic and cleanroom standard processes, the circuit boards can use nanomaterials and polymers as a replacement for silicon technology. This will not only increase the electrical conductivity and thermal stability but will also increase the biodegradability and biocompatibility of the sensors. The fabrication process to form the POC circuitry can also be altered to form fully integrated fast, portable, low-cost and easy-to-use systems with high sensitivity and specificity [128]. They will help to detect in controlled environments but can be used by non-expert people to perform a long-term study in the change in the concentrations over the due course of time. Ferromagnetic materials other than $\mathrm{Fe}_{3} \mathrm{O}_{4}$ particles should be considered for magnetizing the prototypes. These particles are prone to oxidation in the air due to their high surface chemical activity on their surface [129]. The consideration of forming sensor arrays to detect different types of aflatoxin compounds can also be done in order to reduce the sensor cost and detection time. The POC devices can also be embedded with wireless communication protocols so that the precise concentration of the aflatoxin compounds in milk and other food products can be displayed in local grocery stores and supermarkets. This will assist consumers in deciding if the milk should be bought or not. A dynamic thresholding value [130] can be set so that the change in the concentrations of aflatoxin compounds with respect to certain parameters such as days, type of milk, storage temperature, storage material and others can be monitored. With respect to the detection techniques used in conjugation with these sensors, optical sensing techniques work better in terms of faster response, higher spatial resolution and lower detection limits. This technique should be further employed to detect ATM1 in milk [131] to help these carbon allotropes-based sensors achieve better performances.

\section{Conclusions and Future Perspectives}

The paper highlights the use of CNTs and graphene to develop sensors that have successfully detected ATM1 and AFB1 compounds at varying concentrations. The advantages of these types of sensors include high biocompatibility, easy operating principles and quick fabrication and detection processes. These nanomaterials have been used in both pure and composite forms, in which graphene has been considered in certain shapes such as quantum dots, nanosheets and nanoparticles. The conjugation of these carbon-based allotropes has been done with other nanomaterials such as crystalline compounds and 
conductive metallic nanoparticles to increase the sensitivity of the sensing area. The selectivity of these prototypes has been increased by attaching primary antibodies so that they show enhanced performances even in the presence of other interfering molecules. The magnetic properties of these sensors have also been altered by treating them with certain ferromagnetic materials. The availability of the prototypes mentioned above for the detection of aflatoxin compounds has provided a strong podium in microelectronics, which can help future researchers develop sensors for the detection of different kinds of biomolecules present in food products.

Further work can be done on enhancing the fabrication and implementation sides of these sensors. In order to develop these sensors, low-cost 3D printed sensors can be developed via an additive manufacturing process. Customized printers should be designed for quick roll-to-roll production of these sensors. Since the addition of a selective layer creates an issue of reusability, the fabrication part should include the processing nanomaterials that form the selective layer. The materials that are chosen to form the selective layer should be more biodegradable and biocompatible material as a replacement to metallic nanomaterials. In terms of detection mechanisms, certain processes such as chromatography and optical techniques should be encouraged ahead of impedance spectroscopic techniques. This will not only help in conducting the experiments with low sample volumes and obtain a precise detection but will also aid in avoiding certain circumstances such as reducing the ambient noise and the minimization of theoretical simulations and complex data analysis for quantification [132]. The single-use sensors can also be motivated in order to avoid sensitivity drift problems and storage issues. The further focus should be given to food packaging industries to integrate these sensors with milk bottles and other food products. The substrates of the prototypes can be replaced with bioplastics in order to make the sensors biocompatible and increase their overall thermal tolerance. The sensors would help to obtain real-time data with regards to the change in the concentration of aflatoxin levels with the help of color-coded statuary warning charts. Research projects should be proposed with a collaboration between the academic groups and food packaging industries so that the sensors fabricated in a controlled laboratory environment can be simultaneously tested in real-time situations. Thorough scrutiny should be done on the expiry and consumable dates of the dairy products so that a maximum number of consumers can avoid the effects caused by the excess amount of aflatoxins in the body. The milk obtained from the dairy cows should be pasteurized properly before packaging, storing and consumption. This is because the food habits of some of the dairy cows contain mycotoxins, which are metalized into carcinogenic ATM1 and are subsequently eliminated through milk [133]. In a broader sense, a classification should be done on the quality of milk available in local stores and supermarkets on the basis of the chemical compounds present in them and the health hazards they can cause when increased beyond a certain threshold. This should also be reflected on the expiry dates so that consumers can have a safe range for their consumption plan. The electronics embedded with the sensors can consist of radio-frequency identification (RFID) tags or other flexible wireless protocols that can immediately send the data within specific ranges. This will be helpful to keep a regular check on the concentration of the aflatoxin, especially in cases of the changes happening in storage and the environment.

Author Contributions: Conception and design, J.G., S.H. and A.N.; collection and assembly of data, J.G., S.H., A.N. and J.W.C.W.; Writing-Original Draft Preparation, A.N.; Writing-Review and Editing, A.N. and J.W.C.W.; supervision, J.G., S.H. and J.W.C.W.; funding, J.G. and S.H. All authors have read and agreed to the published version of the manuscript.

Funding: No funding is achieved.

Institutional Review Board Statement: Not applicable.

Informed Consent Statement: Not applicable.

Data Availability Statement: Not applicable. 
Conflicts of Interest: The authors declare no conflict of interest.

\section{References}

1. Bryzek, J. Impact of MEMS technology on society. Sens. Actuators A Phys. 1996, 56, 1-9. [CrossRef]

2. Tilli, M.; Paulasto-Krockel, M.; Petzold, M.; Theuss, H.; Motooka, T.; Lindroos, V. Handbook of Silicon Based MEMS Materials and Technologies; Elsevier: Amsterdam, The Netherlands, 2020.

3. Khan, S.; Lorenzelli, L.; Dahiya, R.S. Technologies for printing sensors and electronics over large flexible substrates: A review. IEEE Sens. J. 2014, 15, 3164-3185. [CrossRef]

4. Nayak, L.; Mohanty, S.; Nayak, S.K.; Ramadoss, A. A review on inkjet printing of nanoparticle inks for flexible electronics. J. Mater. Chem. C 2019, 7, 8771-8795. [CrossRef]

5. Sze, S.M. Semiconductor Sensors; John Wiley \& Sons: Hoboken, NJ, USA, 1994.

6. Jaaniso, R.; Tan, O.K. Semiconductor Gas Sensors; Elsevier: Amsterdam, The Netherlands, 2013.

7. Advantages and Disadvantages of Silicon Detectors. Available online: https://www.nuclear-power.net/nuclear-engineering/ radiation-detection/semiconductor-detectors/silicon-based-semiconductor-detectors/advantages-and-disadvantages-ofsilicon-detectors / (accessed on 18 May 2021).

8. Subramanian, V.; Lee, T. Nanotechnology-based flexible electronics. Nanotechnology 2012, 23, 340201. [CrossRef] [PubMed]

9. Jeevanandam, J.; Barhoum, A.; Chan, Y.S.; Dufresne, A.; Danquah, M.K. Review on nanoparticles and nanostructured materials: History, sources, toxicity and regulations. Beilstein J. Nanotechnol. 2018, 9, 1050-1074. [CrossRef]

10. Krishna, V.D.; Wu, K.; Su, D.; Cheeran, M.C.; Wang, J.-P.; Perez, A. Nanotechnology: Review of concepts and potential application of sensing platforms in food safety. Food Microbiol. 2018, 75, 47-54. [CrossRef]

11. Sanderson, P.; Delgado-Saborit, J.M.; Harrison, R.M. A review of chemical and physical characterisation of atmospheric metallic nanoparticles. Atmos. Environ. 2014, 94, 353-365. [CrossRef]

12. Schröfel, A.; Kratošová, G.; Šafařík, I.; Šafaříková, M.; Raška, I.; Shor, L.M. Applications of biosynthesized metallic nanoparticlesA review. Acta Biomater. 2014, 10, 4023-4042. [CrossRef]

13. Han, T.; Nag, A.; Afsarimanesh, N.; Akhter, F.; Liu, H.; Sapra, S.; Mukhopadhyay, S.; Xu, Y. Gold/Polyimide-Based Resistive Strain Sensors. Electronics 2019, 8, 565. [CrossRef]

14. Liu, G.; Lu, M.; Huang, X.; Li, T.; Xu, D. Application of gold-nanoparticle colorimetric sensing to rapid food safety screening. Sensors 2018, 18, 4166. [CrossRef]

15. Min, S.-H.; Lee, G.-Y.; Ahn, S.-H. Direct printing of highly sensitive, stretchable, and durable strain sensor based on silver nanoparticles/multi-walled carbon nanotubes composites. Compos. Part. B Eng. 2019, 161, 395-401. [CrossRef]

16. Yuan, Z.; Pei, Z.; Shahbaz, M.; Zhang, Q.; Zhuo, K.; Zhao, C.; Zhang, W.; Ma, X.; Sang, S. Wrinkle Structured Network of Silver-Coated Carbon Nanotubes for Wearable Sensors. Nanoscale Res. Lett. 2019, 14, 356. [CrossRef] [PubMed]

17. Xu, X.; Wang, R.; Nie, P.; Cheng, Y.; Lu, X.; Shi, L.; Sun, J. Copper nanowire-based aerogel with tunable pore structure and its application as flexible pressure sensor. ACS Appl. Mater. Interfaces 2017, 9, 14273-14280. [CrossRef] [PubMed]

18. Zhang, Y.; Li, N.; Xiang, Y.; Wang, D.; Zhang, P.; Wang, Y.; Lu, S.; Xu, R.; Zhao, J. A flexible non-enzymatic glucose sensor based on copper nanoparticles anchored on laser-induced graphene. Carbon 2020, 156, 506-513. [CrossRef]

19. Lamanna, L.; Rizzi, F.; Guido, F.; Algieri, L.; Marras, S.; Mastronardi, V.M.; Qualtieri, A.; De Vittorio, M. Flexible and Transparent Aluminum-Nitride-Based Surface-Acoustic-Wave Device on Polymeric Polyethylene Naphthalate. Adv. Electron. Mater. 2019, 5, 1900095. [CrossRef]

20. Meng, X.; Yang, J.; Liu, Z.; Lu, W.; Sun, Y.; Dai, Y. Non-contact, fibrous cellulose acetate/aluminum flexible electronic-sensor for humidity detecting. Compos. Commun. 2020, 20, 100347. [CrossRef]

21. Nag, A.; Zia, A.I.; Li, X.; Mukhopadhyay, S.C.; Kosel, J. Novel sensing approach for LPG leakage detection: Part I—Operating mechanism and preliminary results. IEEE Sens. J. 2015, 16, 996-1003. [CrossRef]

22. Drake, P.L.; Hazelwood, K.J. Exposure-related health effects of silver and silver compounds: A review. Ann. Occup. Hyg. 2005, 49, 575-585.

23. Nag, A.; Mukhopadhyay, S.C.; Kosel, J. Flexible carbon nanotube nanocomposite sensor for multiple physiological parameter monitoring. Sens. Actuators A Phys. 2016, 251, 148-155. [CrossRef]

24. Huang, J.; Yang, X.; Liu, J.; Her, S.-c.; Guo, J.; Gu, J.; Guan, L. Vibration monitoring based on flexible multi-walled carbon nanotube/polydimethylsiloxane film sensor and the application on motion signal acquisition. Nanotechnology 2020, $31,335504$. [CrossRef]

25. Han, T.; Nag, A.; Mukhopadhyay, S.C.; Xu, Y. Carbon nanotubes and its gas-sensing applications: A review. Sens. Actuators A Phys. 2019, 291, 107-143. [CrossRef]

26. Han, T.; Nag, A.; Simorangkir, R.B.; Afsarimanesh, N.; Liu, H.; Mukhopadhyay, S.C.; Xu, Y.; Zhadobov, M.; Sauleau, R. Multifunctional flexible sensor based on laser-induced graphene. Sensors 2019, 19, 3477. [CrossRef] [PubMed]

27. Nag, A.; Mitra, A.; Mukhopadhyay, S.C. Graphene and its sensor-based applications: A review. Sens. Actuators A Phys. 2018, 270, 177-194. [CrossRef]

28. Alahi, M.E.E.; Nag, A.; Mukhopadhyay, S.C.; Burkitt, L. A temperature-compensated graphene sensor for nitrate monitoring in real-time application. Sens. Actuators A Phys. 2018, 269, 79-90. [CrossRef] 
29. Nag, A.; Alahi, M.E.E.; Feng, S.; Mukhopadhyay, S.C. IoT-based sensing system for phosphate detection using Graphite/PDMS sensors. Sens. Actuators A Phys. 2019, 286, 43-50. [CrossRef]

30. Huang, Y.; Zeng, X.; Wang, W.; Guo, X.; Hao, C.; Pan, W.; Liu, P.; Liu, C.; Ma, Y.; Zhang, Y. High-resolution flexible temperature sensor based graphite-filled polyethylene oxide and polyvinylidene fluoride composites for body temperature monitoring. Sens. Actuators A Phys. 2018, 278, 1-10. [CrossRef]

31. Shih, W.-P.; Tsao, L.-C.; Lee, C.-W.; Cheng, M.-Y.; Chang, C.; Yang, Y.-J.; Fan, K.-C. Flexible temperature sensor array based on a graphite-polydimethylsiloxane composite. Sensors 2010, 10, 3597-3610. [CrossRef]

32. Pan, S.; Pei, Z.; Jing, Z.; Song, J.; Zhang, W.; Zhang, Q.; Sang, S. A highly stretchable strain sensor based on CNT/graphene/fullereneSEBS. RSC Adv. 2020, 10, 11225-11232. [CrossRef]

33. Yasin, M.; Tauqeer, T.; Rahman, H.U.; Karimov, K.S.; San, S.E.; Tunc, A.V. Polymer-fullerene bulk heterojunction-based strainsensitive flexible organic field-effect transistor. Arab. J. Sci. Eng. 2015, 40, 257-262. [CrossRef]

34. Nalwa, K.S.; Cai, Y.; Thoeming, A.L.; Shinar, J.; Shinar, R.; Chaudhary, S. Polythiophene-fullerene based photodetectors: Tuning of spectral response and application in photoluminescence based (bio) chemical sensors. Adv. Mater. 2010, 22, 4157-4161. [CrossRef]

35. Gurunathan, S.; Han, J.W.; Eppakayala, V.; Dayem, A.A.; Kwon, D.-N.; Kim, J.-H. Biocompatibility effects of biologically synthesized graphene in primary mouse embryonic fibroblast cells. Nanoscale Res. Lett. 2013, 8, 393. [CrossRef] [PubMed]

36. Vardharajula, S.; Ali, S.Z.; Tiwari, P.M.; Eroğlu, E.; Vig, K.; Dennis, V.A.; Singh, S.R. Functionalized carbon nanotubes: Biomedical applications. Int. J. Nanomed. 2012, 7, 5361.

37. Nag, A.; Simorangkir, R.B.; Valentin, E.; Björninen, T.; Ukkonen, L.; Hashmi, R.M.; Mukhopadhyay, S.C. A transparent strain sensor based on PDMS-embedded conductive fabric for wearable sensing applications. IEEE Access 2018, 6, 71020-71027. [CrossRef]

38. Nag, A.; Feng, S.; Mukhopadhyay, S.; Kosel, J.; Inglis, D. 3D printed mould-based graphite/PDMS sensor for low-force applications. Sens. Actuators A Phys. 2018, 280, 525-534. [CrossRef]

39. Nag, A.; Mukhopadhyay, S.C.; Kosel, J. Tactile sensing from laser-ablated metallized PET films. IEEE Sens. J. 2016, 17, 7-13. [CrossRef]

40. Yaqoob, U.; Phan, D.-T.; Uddin, A.I.; Chung, G.-S. Highly flexible room temperature $\mathrm{NO}_{2}$ sensor based on $\mathrm{MWCNTs}^{-W O_{3}}$ nanoparticles hybrid on a PET substrate. Sens. Actuators B Chem. 2015, 221, 760-768. [CrossRef]

41. Latessa, G.; Brunetti, F.; Reale, A.; Saggio, G.; Di Carlo, A. Piezoresistive behaviour of flexible PEDOT: PSS based sensors. Sens. Actuators B Chem. 2009, 139, 304-309. [CrossRef]

42. Seekaew, Y.; Lokavee, S.; Phokharatkul, D.; Wisitsoraat, A.; Kerdcharoen, T.; Wongchoosuk, C. Low-cost and flexible printed graphene-PEDOT: PSS gas sensor for ammonia detection. Org. Electron. 2014, 15, 2971-2981. [CrossRef]

43. Nag, A.; Mukhopadhyay, S.C.; Kosel, J. Sensing system for salinity testing using laser-induced graphene sensors. Sens. Actuators A Phys. 2017, 264, 107-116. [CrossRef]

44. Bobinger, M.R.; Romero, F.J.; Salinas-Castillo, A.; Becherer, M.; Lugli, P.; Morales, D.P.; Rodríguez, N.; Rivadeneyra, A. Flexible and robust laser-induced graphene heaters photothermally scribed on bare polyimide substrates. Carbon 2019, 144, 116-126. [CrossRef]

45. Nag, A.; Mukhopadhyay, S.C.; Kosel, J. Wearable flexible sensors: A review. IEEE Sens. J. 2017, 17, 3949-3960. [CrossRef]

46. Zia, A.I.; Mukhopadhyay, S.C.; Yu, P.-L.; Al-Bahadly, I.H.; Gooneratne, C.P.; Kosel, J. Rapid and molecular selective electrochemical sensing of phthalates in aqueous solution. Biosens. Bioelectron. 2015, 67, 342-349. [CrossRef] [PubMed]

47. Afsarimanesh, N.; Nag, A.; Alahi, M.E.E.; Han, T.; Mukhopadhyay, S.C. Interdigital Sensors: Biomedical, Environmental and Industrial Applications. Sens. Actuators A Phys. 2020, 305, 111923. [CrossRef]

48. Nag, A.; Menzies, B.; Mukhopadhyay, S.C. Performance analysis of flexible printed sensors for robotic arm applications. Sens. Actuators A Phys. 2018, 276, 226-236. [CrossRef]

49. Devaraj, H.; Schober, R.; Picard, M.; Teo, M.Y.; Lo, C.-Y.; Gan, W.C.; Aw, K.C. Highly Elastic and Flexible Multi-layered Carbon Black/Elastomer Composite based Capacitive Sensor Arrays for Soft Robotics. Meas. Sens. 2020, 2, 100004. [CrossRef]

50. Dahiya, A.S.; Gil, T.; Thireau, J.; Azemard, N.; Lacampagne, A.; Charlot, B.; Todri-Sanial, A. 1D Nanomaterial-Based Highly Stretchable Strain Sensors for Human Movement Monitoring and Human-Robotic Interactive Systems. Adv. Electron. Mater. 2020, 6, 2000547. [CrossRef]

51. Iijima, S. Synthesis of carbon nanotubes. Nature 1991, 354, 56-58. [CrossRef]

52. Dresselhaus, M.S.; Dresselhaus, G.; Eklund, P.; Rao, A. Carbon nanotubes. In The Physics of Fullerene-Based and Fullerene-Related Materials; Springer: Berlin/Heidelberg, Germany, 2000; pp. 331-379.

53. Chen, J.; Hamon, M.A.; Hu, H.; Chen, Y.; Rao, A.M.; Eklund, P.C.; Haddon, R.C. Solution properties of single-walled carbon nanotubes. Science 1998, 282, 95-98. [CrossRef] [PubMed]

54. Hirsch, A. Functionalization of single-walled carbon nanotubes. Angew. Chem. Int. Ed. 2002, 41, 1853-1859. [CrossRef]

55. Li, J.; Stevens, R.; Delzeit, L.; Ng, H.T.; Cassell, A.; Han, J.; Meyyappan, M. Electronic properties of multiwalled carbon nanotubes in an embedded vertical array. Appl. Phys. Lett. 2002, 81, 910-912. [CrossRef]

56. Koinkar, P.; Ohsumi, Y.; Kanazawa, M.; Furube, A.; Gavhane, D.; More, M.A. Field emission properties of laser ablated multi-walled carbon nanotubes. Int. J. Mod. Phys. B 2018, 32, 1840045. [CrossRef]

57. Wei, J.; Zhu, H.; Jiang, B.; Ci, L.; Wu, D. Electronic properties of double-walled carbon nanotube films. Carbon 2003, 41, 2495-2500. [CrossRef] 
58. Tang, D.; Ci, L.; Zhou, W.; Xie, S. Effect of $\mathrm{H} 2 \mathrm{O}$ adsorption on the electrical transport properties of double-walled carbon nanotubes. Carbon 2006, 44, 2155-2159. [CrossRef]

59. Feng, Y.; Zhang, H.; Hou, Y.; McNicholas, T.P.; Yuan, D.; Yang, S.; Ding, L.; Feng, W.; Liu, J. Room temperature purification of few-walled carbon nanotubes with high yield. ACS Nano 2008, 2, 1634-1638. [CrossRef] [PubMed]

60. Hou, Y.; Tang, J.; Zhang, H.; Qian, C.; Feng, Y.; Liu, J. Functionalized few-walled carbon nanotubes for mechanical reinforcement of polymeric composites. ACS Nano 2009, 3, 1057-1062. [CrossRef] [PubMed]

61. Somanathan, T.; Pandurangan, A. Helical multiwalled carbon nanotubes (h-MWCNTs) synthesized by catalytic chemical vapor deposition. New Carbon Mater. 2010, 25, 175-180. [CrossRef]

62. Venkatesan, S.; Visvalingam, B.; Mannathusamy, G.; Viswanathan, V.; Rao, A.G. Effect of chemical vapor deposition parameters on the diameter of multi-walled carbon nanotubes. Int. Nano Lett. 2018, 8, 297-308. [CrossRef]

63. Roslan, M.; Chaudhary, K.; Doylend, N.; Agam, A.; Kamarulzaman, R.; Haider, Z.; Mazalan, E.; Ali, J. Growth of wall-controlled MWCNTs by magnetic field assisted arc discharge plasma. J. Saudi Chem. Soc. 2019, 23, 171-181. [CrossRef]

64. Sari, A.H.; Khazali, A.; Parhizgar, S.S. Synthesis and characterization of long-CNTs by electrical arc discharge in deionized water and $\mathrm{NaCl}$ solution. Int. Nano Lett. 2018, 8, 19-23. [CrossRef]

65. Mwafy, E.A.; Mostafa, A.M. Multi walled carbon nanotube decorated cadmium oxide nanoparticles via pulsed laser ablation in liquid media. Opt. Laser Technol. 2019, 111, 249-254. [CrossRef]

66. Hirahara, K.; Suenaga, K.; Bandow, S.; Iijima, S. Boron-catalyzed multi-walled carbon nanotube growth with the reduced number of layers by laser ablation. Chem. Phys. Lett. 2000, 324, 224-230. [CrossRef]

67. Novoselova, I.; Oliinyk, N.; Volkov, S.; Konchits, A.; Yanchuk, I.; Yefanov, V.; Kolesnik, S.; Karpets, M. Electrolytic synthesis of carbon nanotubes from carbon dioxide in molten salts and their characterization. Phys. E Low-Dimens. Syst. Nanostruc. 2008, 40, 2231-2237. [CrossRef]

68. Abbasloo, S.; Ojaghi-Ilkhchi, M.; Mozammel, M. Synthesis of Carbon Nanotubes by Molten Salt Electrolysis: A Review. Available online: https://www.researchgate.net/profile/Soodeh-Abbasloo/publication/325451967_Synthesis_of_carbon_nanotubes_ by_molten_salt_electrolysis_a_review/links/5c8dcec645851564fae2a77f/Synthesis-of-carbon-nanotubes-by-molten-saltelectrolysis-a-review.pdf (accessed on 18 May 2021).

69. Geim, A.K.; Novoselov, K.S. The rise of graphene. In Nanoscience and Technology: A Collection of Reviews from Nature Journals; World Scientific: Berlin, Germany, 2010; pp. 11-19.

70. Zeng, J.; Ji, X.; Ma, Y.; Zhang, Z.; Wang, S.; Ren, Z.; Zhi, C.; Yu, J. 3D graphene fibers grown by thermal chemical vapor deposition. Adv. Mater. 2018, 30, 1705380. [CrossRef] [PubMed]

71. Wang, X.; Qiu, Y.; Cao, W.; Hu, P. Highly stretchable and conductive core-sheath chemical vapor deposition graphene fibers and their applications in safe strain sensors. Chem. Mater. 2015, 27, 6969-6975. [CrossRef]

72. Chen, J.; Yao, B.; Li, C.; Shi, G. An improved Hummers method for eco-friendly synthesis of graphene oxide. Carbon 2013, 64, 225-229. [CrossRef]

73. Zaaba, N.; Foo, K.; Hashim, U.; Tan, S.; Liu, W.-W.; Voon, C. Synthesis of graphene oxide using modified hummers method: Solvent influence. Procedia Eng. 2017, 184, 469-477. [CrossRef]

74. Lin, J.; Peng, Z.; Liu, Y.; Ruiz-Zepeda, F.; Ye, R.; Samuel, E.L.; Yacaman, M.J.; Yakobson, B.I.; Tour, J.M. Laser-induced porous graphene films from commercial polymers. Nat. Commun. 2014, 5, 5714. [CrossRef]

75. Kaidarova, A.; Alsharif, N.; Oliveira, B.N.M.; Marengo, M.; Geraldi, N.R.; Duarte, C.M.; Kosel, J. Laser-Printed, Flexible Graphene Pressure Sensors. Glob. Chall. 2020, 4, 2000001. [CrossRef] [PubMed]

76. Radhakrishnan, S.; Mathiyarasu, J. Graphene-carbon nanotubes modified electrochemical sensors. In Graphene-Based Electrochemical Sensors for Biomolecules; Elsevier: Amsterdam, The Netherlands, 2019; pp. 187-205.

77. Immanuel, S.; Aparna, T.; Sivasubramanian, R. Graphene-Metal Oxide Nanocomposite Modified Electrochemical Sensors. In Graphene-Based Electrochemical Sensors for Biomolecules; Elsevier: Amsterdam, The Netherlands, 2019; pp. 113-138.

78. Thompson, B.C.; Murray, E.; Wallace, G.G. Graphite oxide to graphene. Biomaterials to bionics. Adv. Mater. 2015, 27, 7563-7582. [CrossRef]

79. Fakhri, Y.; Rahmani, J.; Oliveira, C.A.F.; Franco, L.T.; Corassin, C.H.; Saba, S.; Rafique, J.; Khaneghah, A.M. Aflatoxin M1 in human breast milk: A global systematic review, meta-analysis, and risk assessment study (Monte Carlo simulation). Trends Food Sci. Technol. 2019, 88, 333-342. [CrossRef]

80. Mohammadi, H. A review of aflatoxin M1, milk, and milk products. In Flatoxins-Biochemistry and Molecular Biology; InTech: London, UK, 2011; pp. 397-414.

81. Jia, Y.; Zhou, G.; Liu, P.; Li, Z.; Yu, B. Recent development of aptamer sensors for the quantification of aflatoxin B1. Appl. Sci. 2019, 9, 2364. [CrossRef]

82. Salari, N.; Kazeminia, M.; Vaisi-Raygani, A.; Jalali, R.; Mohammadi, M. Aflatoxin M1 in Milk Worldwide from 1988 to 2020 A Systematic Review and Meta-Analysis. J. Food Qual. 2020, 2020, 8862738. [CrossRef]

83. Xu, X.; Liu, X.; Li, Y.; Ying, Y. A simple and rapid optical biosensor for detection of aflatoxin B1 based on competitive dispersion of gold nanorods. Biosens. Bioelectron. 2013, 47, 361-367. [CrossRef]

84. Sharma, A.; Kumar, A.; Khan, R. A highly sensitive amperometric immunosensor probe based on gold nanoparticle functionalized poly (3,4-ethylenedioxythiophene) doped with graphene oxide for efficient detection of aflatoxin B1. Synth. Met. 2018, 235, 136-144. [CrossRef] 
85. Gan, N.; Zhou, J.; Xiong, P.; Hu, F.; Cao, Y.; Li, T.; Jiang, Q. An ultrasensitive electrochemiluminescent immunoassay for Aflatoxin M1 in milk, based on extraction by magnetic graphene and detection by antibody-labeled CdTe quantumn dots-carbon nanotubes nanocomposite. Toxins 2013, 5, 865-883. [CrossRef]

86. Geleta, G.S.; Zhao, Z.; Wang, Z. A novel reduced graphene oxide/molybdenum disulfide/polyaniline nanocomposite-based electrochemical aptasensor for detection of aflatoxin B 1. Analyst 2018, 143, 1644-1649. [CrossRef] [PubMed]

87. Kaminiaris, M.D.; Mavrikou, S.; Georgiadou, M.; Paivana, G.; Tsitsigiannis, D.I.; Kintzios, S. An Impedance Based Electrochemical Immunosensor for Aflatoxin B1 Monitoring in Pistachio Matrices. Chemosensors 2020, 8, 121. [CrossRef]

88. Mwanza, M.; Abdel-Hadi, A.; Ali, A.M.; Egbuta, M. Evaluation of analytical assays efficiency to detect aflatoxin M1 in milk from selected areas in Egypt and South Africa. J. Dairy Sci. 2015, 98, 6660-6667. [CrossRef]

89. Pitroda, J.; Jethwa, B.; Dave, S. A critical review on carbon nanotubes. Int. J. Constr. Res. Civ. Eng. 2016, 2, 36-42.

90. Matabaro, E.; Ishimwe, N.; Uwimbabazi, E.; Lee, B.H. Current immunoassay methods for the rapid detection of aflatoxin in milk and dairy products. Compr. Rev. Food Sci. Food Saf. 2017, 16, 808-820. [CrossRef]

91. Orazem, M.E.; Tribollet, B. Electrochemical Impedance Spectroscopy. New Jersey 2008. Available online: https:/ /iopscience.iop org / article/10.1149/2.20192if/pdf\#page=50 (accessed on 18 May 2021).

92. Lasia, A. Electrochemical impedance spectroscopy and its applications. In Modern Aspects of Electrochemistry; Springer: Berlin/Heidelberg, Germany, 2002; pp. 143-248.

93. Elgrishi, N.; Rountree, K.J.; McCarthy, B.D.; Rountree, E.S.; Eisenhart, T.T.; Dempsey, J.L. A practical beginner's guide to cyclic voltammetry. J. Chem. Educ. 2018, 95, 197-206. [CrossRef]

94. Costentin, C.; Fortage, J.; Collomb, M.-N. Electrophotocatalysis: Cyclic Voltammetry as an Analytical Tool. J. Phys. Chem. Lett. 2020, 11, 6097-6104. [CrossRef] [PubMed]

95. Veerakumar, P.; Sangili, A.; Chen, S.-M.; Vinothkumar, V.; Balu, S.; Hung, S.-T.; Lin, K.-C. Zinc and Sulfur Codoped Iron Oxide Nanocubes Anchored on Carbon Nanotubes for the Detection of Antitubercular Drug Isoniazid. ACS Appl. Nano Mater. 2021. [CrossRef]

96. Keru, G.; Ndungu, P.G.; Nyamori, V.O. Nitrogen-doped carbon nanotubes synthesised by pyrolysis of (4-\{[(pyridine-4-yl) methylidene] amino\} phenyl) ferrocene. J. Nanomater. 2013, 2013, 750318. [CrossRef]

97. Mabena, L.F.; Ray, S.S.; Mhlanga, S.D.; Coville, N.J. Nitrogen-doped carbon nanotubes as a metal catalyst support. Appl. Nanosci. 2011, 1, 67-77. [CrossRef]

98. Tan, Z.; Li, H.; Feng, Q.; Jiang, L.; Pan, H.; Huang, Z.; Zhou, Q.; Zhou, H.; Ma, S.; Kuang, Y. One-pot synthesis of Fe/N/S-doped porous carbon nanotubes for efficient oxygen reduction reaction. J. Mater. Chem. A 2019, 7, 1607-1615. [CrossRef]

99. $\mathrm{Hu}, \mathrm{C} . ; \mathrm{Hu}, \mathrm{S}$. Carbon nanotube-based electrochemical sensors: Principles and applications in biomedical systems. J. Sens. 2009, 2009, 187615. [CrossRef]

100. Gao, J.; Wang, X.; Zhang, Y.; Liu, J.; Lu, Q.; Liu, M. Boron-doped ordered mesoporous carbons for the application of supercapacitors. Electrochim. Acta 2016, 207, 266-274. [CrossRef]

101. Zheng, W.; Teng, J.; Cheng, L.; Ye, Y.; Pan, D.; Wu, J.; Xue, F.; Liu, G.; Chen, W. Hetero-enzyme-based two-round signal amplification strategy for trace detection of aflatoxin B1 using an electrochemical aptasensor. Biosens. Bioelectron. 2016, 80, 574-581. [CrossRef]

102. Ahammad, A.; Lee, J.-J.; Rahman, M. Electrochemical sensors based on carbon nanotubes. Sensors 2009, 9, 2289. [CrossRef]

103. Zhao, Y.; Yuan, Y.-C.; Bai, X.-L.; Liu, Y.-M.; Wu, G.-F.; Yang, F.-S.; Liao, X. Multi-mycotoxins analysis in liquid milk by UHPLC-QExactive HRMS after magnetic solid-phase extraction based on PEGylated multi-walled carbon nanotubes. Food Chem. 2020, 305, 125429. [CrossRef] [PubMed]

104. Singh, C.; Srivastava, S.; Ali, M.A.; Gupta, T.K.; Sumana, G.; Srivastava, A.; Mathur, R.; Malhotra, B.D. Carboxylated multiwalled carbon nanotubes based biosensor for aflatoxin detection. Sens. Actuators B Chem. 2013, 185, 258-264. [CrossRef]

105. Zhang, S.; Shen, Y.; Shen, G.; Wang, S.; Shen, G.; Yu, R. Electrochemical immunosensor based on Pd-Au nanoparticles supported on functionalized PDDA-MWCNT nanocomposites for aflatoxin B1 detection. Anal. Biochem. 2016, 494, 10-15. [CrossRef]

106. Li, W.-k.; Zhang, H.-x.; Shi, Y.-p. Simultaneous determination of aflatoxin B1 and zearalenone by magnetic nanoparticle filled amino-modified multi-walled carbon nanotubes. Anal. Methods 2018, 10, 3353-3363. [CrossRef]

107. Costa, M.P.; Frías, I.A.; Andrade, C.A.; Oliveira, M.D. Impedimetric immunoassay for aflatoxin B1 using a cysteine modified gold electrode with covalently immobilized carbon nanotubes. Microchim. Acta 2017, 184, 3205-3213. [CrossRef]

108. Li, N.; Qiu, J.; Qian, Y. Polyethyleneimine-modified magnetic carbon nanotubes as solid-phase extraction adsorbent for the analysis of multi-class mycotoxins in milk via liquid chromatography-tandem mass spectrometry. J. Sep. Sci. 2021, 44, 636-644. [CrossRef] [PubMed]

109. Abera, B.D.; Falco, A.; Ibba, P.; Cantarella, G.; Petti, L.; Lugli, P. Development of flexible dispense-printed electrochemical immunosensor for aflatoxin M1 detection in milk. Sensors 2019, 19, 3912. [CrossRef]

110. Varlamova, R.; Medyantseva, E.; Khamidullina, R.; Budnikov, H. Amperometric Tyrosinase Biosensors Based on NanomaterialModified Electrodes for Aflatoxin M1. J. Anal. Chem. 2019, 74, 59-67. [CrossRef]

111. Singha, R.; Kumarb, S. Applications of graphene-based sensors for biomedical industries. Anal. Appl. Graphene Compr. Anal. Chem. 2020, 91, 201.

112. Jia, Y.; Wu, F.; Liu, P.; Zhou, G.; Yu, B.; Lou, X.; Xia, F. A label-free fluorescent aptasensor for the detection of Aflatoxin B1 in food samples using AIEgens and graphene oxide. Talanta 2019, 198, 71-77. [CrossRef] 
113. Guo, X.; Wen, F.; Qiao, Q.; Zheng, N.; Saive, M.; Fauconnier, M.-L.; Wang, J. A novel graphene oxide-based aptasensor for amplified fluorescent detection of aflatoxin M1 in milk powder. Sensors 2019, 19, 3840. [CrossRef]

114. Zhang, X.; Zhang, X.; Song, L.; Huang, X.; Li, Y.; Qiao, M.; Liu, W.; Zhang, T.; Qi, Y.; Wang, W. An ultrasensitive, homogeneous fluorescence quenching immunoassay integrating separation and detection of aflatoxin M 1 based on magnetic graphene composites. Microchim. Acta 2021, 188, 59. [CrossRef] [PubMed]

115. Lu, Z.; Chen, X.; Wang, Y.; Zheng, X.; Li, C.M. Aptamer based fluorescence recovery assay for aflatoxin B1 using a quencher system composed of quantum dots and graphene oxide. Microchim. Acta 2015, 182, 571-578. [CrossRef]

116. Khoshfetrat, S.M.; Bagheri, H.; Mehrgardi, M.A. Visual electrochemiluminescence biosensing of aflatoxin M1 based on luminolfunctionalized, silver nanoparticle-decorated graphene oxide. Biosens. Bioelectron. 2018, 100, 382-388. [CrossRef]

117. Krittayavathananon, A.; Sawangphruk, M. Impedimetric sensor of ss-HSDNA/reduced graphene oxide aerogel electrode toward aflatoxin B1 detection: Effects of redox mediator charges and hydrodynamic diffusion. Anal. Chem. 2017, 89, 13283-13289. [CrossRef]

118. Jiang, K.; Huang, Q.; Fan, K.; Wu, L.; Nie, D.; Guo, W.; Wu, Y.; Han, Z. Reduced graphene oxide and gold nanoparticle compositebased solid-phase extraction coupled with ultra-high-performance liquid chromatography-tandem mass spectrometry for the determination of 9 mycotoxins in milk. Food Chem. 2018, 264, 218-225. [CrossRef] [PubMed]

119. Mo, R.; He, L.; Yan, X.; Su, T.; Zhou, C.; Wang, Z.; Hong, P.; Sun, S.; Li, C. A novel aflatoxin B1 biosensor based on a porous anodized alumina membrane modified with graphene oxide and an aflatoxin B1 aptamer. Electrochem. Commun. 2018, 95, 9-13. [CrossRef]

120. Shadjou, R.; Hasanzadeh, M.; Heidar-poor, M.; Shadjou, N. Electrochemical monitoring of aflatoxin M1 in milk samples using silver nanoparticles dispersed on $\alpha$-cyclodextrin-GQD s nanocomposite. J. Mol. Recognit. 2018, 31, e2699. [CrossRef] [PubMed]

121. Lu, Y.; Zhao, X.; Tian, Y.; Guo, Q.; Li, C.; Nie, G. An electrochemiluminescence aptasensor for the ultrasensitive detection of aflatoxin $\mathrm{B} 1$ based on gold nanorods/graphene quantum dots-modified poly (indole-6-carboxylic acid)/flower-gold nanocomposite. Microchem. J. 2020, 157, 104959. [CrossRef]

122. Althagafi, I.I.; Ahmed, S.A.; El-Said, W.A. Fabrication of gold/graphene nanostructures modified ITO electrode as highly sensitive electrochemical detection of Aflatoxin B1. PLoS ONE 2019, 14, e0210652. [CrossRef]

123. Tezerji, N.S.; Foroughi, M.M.; Bezenjani, R.R.; Jandaghi, N.; Rezaeipour, E.; Rezvani, F. A facile one-pot green synthesis of $\beta$-cyclodextrin decorated porous graphene nanohybrid as a highly efficient adsorbent for extracting aflatoxins from maize and animal feeds. Food Chem. 2020, 311, 125747. [CrossRef] [PubMed]

124. Nguyen, T.; Chidambara, V.A.; Andreasen, S.Z.; Golabi, M.; Linh, Q.T.; Bang, D.D.; Wolff, A. Point-of-Care Devices for Pathogen Detections: The Three Most Important Factors to Realize towards Commercialization. Trac Trends Anal. Chem. 2020, 131, 116004. [CrossRef]

125. OAM, M.S. A Practical Guide to Global Point-of-Care Testing. 2016. Available online: https://www.perlego.com/book/1468460/ a-practical-guide-to-global-pointofcare-testing-pdf (accessed on 18 May 2021).

126. Nguyen, T.; Chidambara Vinayaka, A.; Duong Bang, D.; Wolff, A. A complete protocol for rapid and low-cost fabrication of polymer microfluidic chips containing three-dimensional microstructures used in point-of-care devices. Micromachines 2019, 10, 624. [CrossRef] [PubMed]

127. Nguyen, T.; Zoëga Andreasen, S.; Wolff, A.; Duong Bang, D. From lab on a chip to point of care devices: The role of open source microcontrollers. Micromachines 2018, 9, 403. [CrossRef] [PubMed]

128. Vashist, S.K. Point-of-care diagnostics: Recent advances and trends. Biosensors 2017, 7, 62. [CrossRef] [PubMed]

129. Shen, L.; Li, B.; Qiao, $\mathrm{Y}_{\text {. }} \mathrm{Fe}_{3} \mathrm{O}_{4}$ nanoparticles in targeted drug/gene delivery systems. Materials 2018, 11, 324. [CrossRef] [PubMed]

130. Nag, A.; Mukhopadhyay, S.C. Occupancy detection at smart home using real-time dynamic thresholding of flexiforce sensor. IEEE Sens. J. 2015, 15, 4457-4463. [CrossRef]

131. Ghauri, M.D.; Hussain, S.Z.; Ullah, U.; Ayaz, R.M.A.; Saleem, R.S.Z.; Kiraz, A.; Cheema, M.I. Detection of aflatoxin M1 by fiber cavity attenuated phase shift spectroscopy. Opt. Express 2021, 29, 3873-3881. [CrossRef]

132. Macdonald, J.R.; Johnson, W.B. Fundamentals of impedance spectroscopy. In Impedance Spectroscopy: Theory, Experiment, and Applications; John Wiley \& Sons: New York, NY, USA, 2018; pp. 1-20. [CrossRef]

133. Bellio, A.; Bianchi, D.M.; Gramaglia, M.; Loria, A.; Nucera, D.; Gallina, S.; Gili, M.; Decastelli, L. Aflatoxin M1 in cow's milk: Method validation for milk sampled in northern Italy. Toxins 2016, 8, 57. [CrossRef] 